\title{
Dual Receptor-Targeted and Redox-Sensitive Polymeric Micelles Self-Assembled from a Folic Acid-Hyaluronic Acid-SS-Vitamin E Succinate Polymer for Precise Cancer Therapy
}

This article was published in the following Dove Press journal:

International Journal of Nanomedicine

\author{
Yue Yang' \\ Yunjian $\mathrm{Li}^{\prime}$ \\ Kai Chen' \\ Ling Zhang ${ }^{2}$ \\ Sen Qiao' \\ Guoxin Tan' \\ Fen Chen ${ }^{1,3,4}$ \\ Weisan Pan (D) 1 \\ 'School of Pharmacy, Shenyang \\ Pharmaceutical University, Shenyang \\ I I00 16, People's Republic of China; \\ ${ }^{2}$ Department of Biotherapy, Cancer \\ Research Institute, The First Affiliated \\ Hospital of China Medical University, \\ Shenyang I I000I, People's Republic of \\ China; ${ }^{3}$ Key Laboratory of Ministry of \\ Education for TCM Viscera-State Theory \\ and Applications, Liaoning University of \\ Traditional Chinese Medicine, Shenyang \\ I I 0847, People's Republic of China; \\ ${ }^{4} Z$ hejiang Jingxin Pharmaceutical Co., Ltd, \\ Zhejiang 3/2500, People's Republic of \\ China
}

Correspondence: Weisan Pan School of Pharmacy, Shenyang Pharmaceutical University, Shenyang I 10016, People's Republic of China $\mathrm{Tel} / \mathrm{Fax}+862443520533$

Email pppwwwsss@163.com

Fen Chen

Key Laboratory of Ministry of Education for TCM Viscera-State Theory and Applications, Liaoning University of Traditional Chinese Medicine, Shenyang I 10847, People's Republic of China $\mathrm{Tel} / \mathrm{Fax}+862431207125$

Email chenfenII2I@I63.com
Purpose: Poor site-specific delivery and insufficient intracellular drug release in tumors are inherent disadvantages to successful chemotherapy. In this study, an extraordinary polymeric micelle nanoplatform was designed for the efficient delivery of paclitaxel (PTX) by combining dual receptor-mediated active targeting and stimuli response to intracellular reduction potential.

Methods: The dual-targeted redox-sensitive polymer, folic acid-hyaluronic acid-SS-vitamin E succinate (FHSV), was synthesized via an amidation reaction and characterized by ${ }^{1}$ H-NMR. Then, PTX-loaded FHSV micelles (PTX/FHSV) were prepared by a dialysis method. The physiochemical properties of the micelles were explored. Moreover, in vitro cytological experiments and in vivo animal studies were carried out to evaluate the antitumor efficacy of polymeric micelles.

Results: The PTX/FHSV micelles exhibited a uniform, near-spherical morphology (148.8 \pm $1.4 \mathrm{~nm})$ and a high drug loading capacity $(11.28 \% \pm 0.25)$. Triggered by the high concentration of glutathione, PTX/FHSV micelles could quickly release their loaded drug into the release medium. The in vitro cytological evaluations showed that, compared with Taxol or single receptor-targeted micelles, FHSV micelles yielded higher cellular uptake by the dual receptor-mediated endocytosis pathway, thus leading to significantly superior cytotoxicity and apoptosis in tumor cells but less cytotoxicity in normal cells. More importantly, in the in vivo antitumor experiments, PTX/FHSV micelles exhibited enhanced tumor accumulation and produced remarkable tumor growth inhibition with minimal systemic toxicity.

Conclusion: Our results suggest that this well-designed FHSV polymer has promising potential for use as a vehicle of chemotherapeutic drugs for precise cancer therapy.

Keywords: micelles, paclitaxel, dual-targeted, redox-sensitive, cytotoxicity, antitumor

\section{Introduction}

Malignant tumors seriously threaten human life and health and are a great challenge for treatment worldwide. The development of numerous approaches to treat cancers is urgent. At present, chemotherapy is the most common strategy in cancer treatment. ${ }^{1}$ Among the most commonly used chemotherapeutic drugs, Paclitaxel (PTX), a microtubule-stabilizing agent, has a considerably wide chemotherapeutic range against various malignant tumors. ${ }^{2-4}$ However, the therapeutic capacity of PTX is extremely inhibited by its low therapeutic index and poor water solubility. ${ }^{5,6}$ To address 
these problems, Taxol ${ }^{\circledR}$, a commercial formulation of PTX, was formulated by dissolving PTX in a 50:50 (v/v) mixture of Cremophor EL and dehydrated ethanol. Nevertheless, a series of Cremophor EL-dependent side effects, including hypersensitivity, myelosuppression and neurotoxicity, heavily restrict the clinical effects of Taxol ${ }^{\circledR .7,8}$ As a result, in 2005, an albumin-bound PTX nanoparticle (Abraxane ${ }^{\circledR}$ ) was approved by the United States Food and Drug Administration (FDA). Although avoiding the side effects of Cremophor EL, Phase III clinical trials of Abraxane ${ }^{\circledR}$ still reveal the appearance of neutropenia and sensory neuropathy in patients. ${ }^{9,10}$ In view of this, a low-toxicity and efficient delivery system for PTX is urgently needed.

Recently, many new drug delivery platforms for PTX, including prodrugs, ${ }^{11}$ liposomes, ${ }^{12}$ solid lipid nanoparticles ${ }^{13}$ and polymeric micelles, ${ }^{14}$ have emerged to circumvent the drawbacks of PTX. Polymeric micelles have been regarded as an effective nanoplatform because of their ability to encapsulate hydrophobic agents into their "coreshell" structure and deliver these agents to tumor regions by the enhanced permeability and retention (EPR) effect. Nevertheless, this EPR effect only facilitates the accumulation of micelles in tumors, and insufficient intracellular uptake remains a great challenge for effective chemotherapy. ${ }^{15,16}$ To overcome the limitation of the EPR effect, researchers have proposed that tumor cell-specific ligands be utilized as targeting moieties to improve the internalization of micelles within tumor sites. Accordingly, modified micelles bearing multiple tumortargeted ligands, such as peptides, ${ }^{17}$ transferrin, ${ }^{18}$ folic acid (FA) ${ }^{19}$ and hyaluronic acid (HA), ${ }^{20}$ have been developed, which can readily enter cancer cells via receptormediated endocytosis rather than by relying on the EPR effect alone, thus obviously enhancing the antitumor efficacy and reducing systematic toxicity. Owning to its nontoxicity, low immunogenicity, high biodegradability and biocompatibility, HA has been widely applied in pharmaceutical fields. ${ }^{21}$ Moreover, HA possesses a selective binding affinity to receptors, such as cluster determinant 44 (CD44) receptor, that are overexpressed within numerous tumors and thus can act as a ligand for active tumor targeting. $^{22,23}$ Based on the strengths mentioned above, a variety of hydrophobic agents, such as deoxycholic acid, ${ }^{24}$ poly(L-histidine) ${ }^{25}$ and stearic acid, ${ }^{26}$ have been chemically conjugated to the backbones of HA to assemble into micelles for targeted delivery of anticancer drugs. However, the aggregation and saturation of receptors might be nonnegligible blocking factors for CD44- mediated internalization, resulting in compromised targeting efficiency. ${ }^{27}$ To address these complicated problems, dual receptor-targeted strategies have drawn great attention from researchers. ${ }^{27-29}$ Dual ligand-modified micelles can be developed to recognize two different receptors of tumor cells, thus producing a synergistic targeting capability. As reported, FA not only has low immunogenicity, storage stability and ready availability but also possesses a high binding affinity to FA receptor (FR) which is overexpressed in several carcinomas but only at low levels in normal cells. $^{30,31}$ When FA-modified nanoparticles encounter with FR presented on the surface of tumor cells, they are easily captured into cells by the ligand-receptor binding effect. More importantly, the simultaneous overexpression of the CD44 receptor and FR on several tumor cells has been reported. ${ }^{32-34}$ For example, Lee et al synthesized amphiphilic HA derivative along with $6.5 \%$ FA substitution. ${ }^{35}$ Similarly, Liu et al also adopted FA- and HA-modified micelles to enhance cellular uptake. ${ }^{34}$ However, we noticed that these micelles exhibit incomplete and delayed drug release after internalization by tumor cells, which has become a crucial explanation for the compromised treatment outcomes. Hence, intelligent dual-targeted micelles based on the binding of HA to CD44 receptor and FA to FR should be rationally designed, which can not only improve the targeting capacity of micelles but also guarantee on-demand intracellular drug release.

Recently, stimuli-responsive micelles have been developed to trigger rapid and complete drug release in tumor cells according to the unique physiological conditions of the tumor microenvironment. ${ }^{36,37}$ It is generally known that the concentration of glutathione (GSH) in the tumor intracellular milieu is much higher than that of the extracellular milieu. ${ }^{38}$ This redox-heterogeneous environment provides the basis of on-demand drug release at tumor sites. Among them, disulfide bonds have been commonly used as redox-responsive linkages. They are relatively stable in blood circulation but cleave by means of thiol-disulfide exchanges in the presence of GSH stimuli once entering tumor cells. ${ }^{39}$ As a result, shell-sheddable micelles with disulfide linkages between hydrophilic shells and hydrophobic cores can be exploited to respond to overproduced GSH in tumor cells, achieving precise and rapid drug release.

In this study, we, for the first time, synthesized an amphiphilic folic acid-hyaluronic acid-SS-vitamin E succinate (FHSV) polymer by utilizing both HA and FA as tumor-targeted ligands and disulfide bonds as redoxresponsive linkages for on-demand intracellular delivery 
of PTX in tumor therapy. (Figure 1) In addition, vitamin E succinate (VES) was selected as the hydrophobic core due to its highly selective toxicity towards tumor cells but low toxicity towards healthy cells. ${ }^{40}$ The redox sensitivity and tunable drug release behavior were studied under high concentration of GSH. Furthermore, in vitro cytotoxicity, apoptosis and cellular uptake studies were performed in human breast cancer cell (MCF-7) and mice embryonic fibroblast cells (NIH3T3 cells). Last, a series of in vivo studies were comprehensively conducted to investigate the anticancer activity and biological safety of this innovative and targeted drug delivery system.

\section{Materials and Methods}

\section{Materials}

Hyaluronic acid (HA, MW=8000 kDa) was obtained from Freda Biochem Co., Ltd. (Shandong, China). Vitamin E succinate (VES), cystamine dihydrochloride $(\mathrm{CYS} \cdot 2 \mathrm{HCl})$, coumarin $6(\mathrm{C} 6)$, glutathione $(\mathrm{GSH})$ and folic acid (FA) were all bought from Aladdin Bio-Chem Technology Co., Ltd (Shanghai, China). Ethylene diamine
(EDA) was purchased from Sinopharm Chemical Reagent Co., Ltd. (Shanghai, China). Paclitaxel (PTX) of purity 99\% and DiR were bought from Dalian Meilun Biotechnology Co., Ltd. (Dalian, China). 1-Ethyl-3(3-dimethylaminopropyl) carbodiimide (EDC), N-hydroxysuccinimide (NHS) and N, N'-dicyclohexylcarbodiimide (DCC) were obtained from Shanghai Medpep Co., Ltd (Shanghai, China). 4',6-diamidino-2-phenylindole (DAPI), 3-(4,5-dimethyl-2-thiazolyl)-2,5-diphenyl-2-H-tetrazolium bromide (MTT), 4\% paraformaldehyde and Annexin V-FITC/propodium iodide (Annexin V-FITC/PI) Apoptosis Detection Kit were provided by Beyotime Institute of Biotechnology (Shanghai, China).

\section{Cell Culture}

MCF-7 cells and NIH3T3 cells were provided by the Chinese Academy of Sciences Cell bank (Shanghai, China). MCF-7 cells were cultured in Roswell Park Memorial Institute 1640 (RPMI 1640) medium, and NIH3T3 cells were cultured in Dulbecco's modified eagle's medium (DMEM). Both cell culture media were

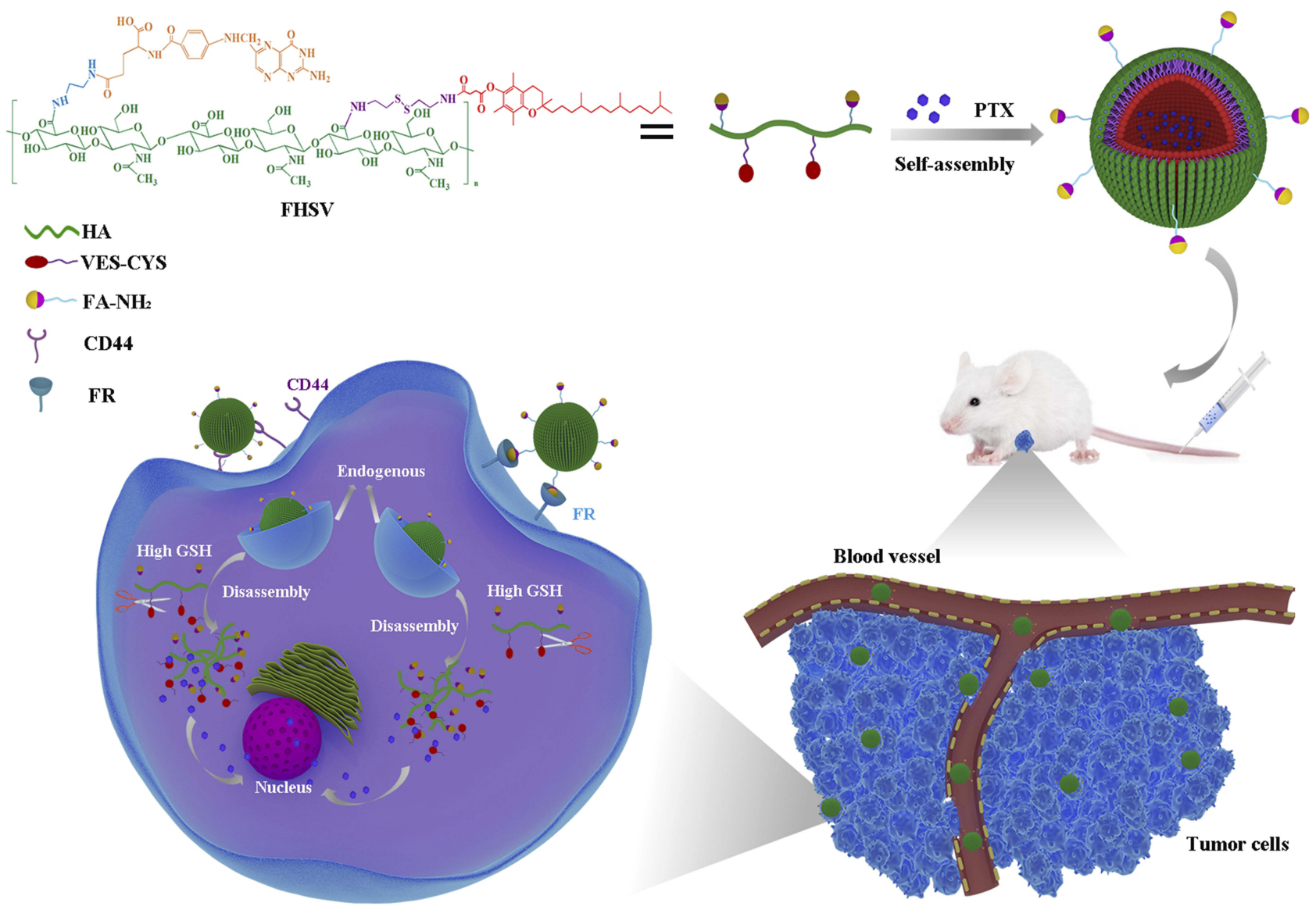

Figure I Illustration of self-assembly, tumor accumulation and intracellular release of PTX/FHSV micelles. 
supplemented with $10 \%(\mathrm{v} / \mathrm{v})$ FBS and $1 \%$ penicillinstreptomycin solution in a humidified atmosphere with $5 \%$ $\mathrm{CO}_{2}$ at $37^{\circ} \mathrm{C}$.

\section{Synthesis of VES-CYS and VES-EDA Linkers}

VES was modified with cystamine (CYS) via an amidation reaction. In detail, VES (1 mmol), EDC ( $2 \mathrm{mmol})$ and NHS $(2 \mathrm{mmol})$ were dispersed in $20 \mathrm{~mL}$ of DMF to activate the carboxylic groups of VES for $2 \mathrm{~h}$. Later, $5 \mathrm{~mL}$ of DMF solution of CYS $2 \mathrm{HCl}(3 \mathrm{mmol})$ and triethylamine (TEA, $400 \mu \mathrm{L}$ ) stirred for $1 \mathrm{~h}$ in advance were added. After $24 \mathrm{~h}$ of stirring at ambient temperature, the solution was extracted several times with distilled water and dichloromethane to remove excess activators and CYS and then dried under vacuum to obtain VESCYS. The structure of VES-CYS was characterized by ${ }^{1} \mathrm{H}$-nuclear magnetic resonance $\left({ }^{1} \mathrm{H}-\mathrm{NMR}\right)$ in DMSO- $d_{6}$ (Figure S1A): $\delta(\mathrm{ppm}) 0.78\left(12 \mathrm{H}, 4 \mathrm{CH}_{3}\right), 0.98-1.54(21 \mathrm{H}$, the aliphatic methylene protons), $2.78\left(4 \mathrm{H}, 2 \mathrm{CH}_{2} \mathrm{~S}\right), 3.12$ $\left(2 \mathrm{H}, \mathrm{CH}_{2} \mathrm{NH}\right), 3.32\left(2 \mathrm{H}, \mathrm{CH}_{2} \mathrm{NH}_{2}\right)$. As a control, the nonreductive VES-EDA linker was synthesized as described above using EDA instead of CYS and TEA. The structure of VES-EDA was confirmed by ${ }^{1} \mathrm{H}-\mathrm{NMR}$ in DMSO- $d_{6}$ (Figure S1A): $\delta(\mathrm{ppm}): 0.78\left(12 \mathrm{H}, 4 \mathrm{CH}_{3}\right), 0$.98-1.54 $(21 \mathrm{H}$, the aliphatic methylene protons), $2.59\left(2 \mathrm{H}, \mathrm{CH}_{2} \mathrm{NH}\right), 3.01\left(2 \mathrm{H}, \mathrm{CH}_{2} \mathrm{NH}_{2}\right)$.

\section{Synthesis of HA-CYS-VES (HSV) and HA-EDA-VES (HCV) Polymers}

The amphiphilic HSV and HCV polymers were prepared by conjugating VES-CYS and VES-EDA to the backbone of HA, respectively, as reported previously with some modifications. ${ }^{41}$ Briefly, HA (1 mmol) was activated for 2 $\mathrm{h}$ in $20 \mathrm{~mL}$ of formamide with the help of EDC (1.5 mmol) and NHS $(1.5 \mathrm{mmol})$ in an ice bath. Next, $0.5 \mathrm{~mol}$ of VESCYS or VES-EDA in $80 \mathrm{~mL}$ of DMF was added dropwise and then stirred overnight. Excess precooled acetone was added to precipitate the reaction solution. After rinsing thrice with cold acetone, the precipitation was redissolved in water and then dialyzed against excess distilled water for 3 days. Subsequently, HSV and HCV polymers were collected by lyophilization.

\section{Synthesis of Amphiphilic FHSV Polymer}

To synthesize the FHSV polymer, the amination of FA was first performed according to the published literature with some modifications. ${ }^{42}$ Briefly, DCC, NHS and FA were first dispersed in $20 \mathrm{~mL}$ of DMSO at a molar ratio of 1.5: 1.5: 1 . After stirring at $50{ }^{\circ} \mathrm{C}$ for $6 \mathrm{~h}$, excess EDA and pyridine were added, and that mixture continued to react overnight at ambient temperature. Then, the reaction solution was precipitated in diethyl ether thrice. The product was dried under vacuum for $12 \mathrm{~h}$ to obtain the yellow powder of FA-NH $\mathrm{N}_{2}$. The FA- $\mathrm{NH}_{2}$ was characterized by ${ }^{1} \mathrm{H}-\mathrm{NMR}$ in DMSO- $d_{6}$ (Figure S1B): $\delta(\mathrm{ppm}): 2.60(2 \mathrm{H}$, $\left.\mathrm{CH}_{2} \mathrm{NH}\right), 3.07\left(2 \mathrm{H}, \mathrm{CH}_{2} \mathrm{NH}_{2}\right), 6.65-7.64(4 \mathrm{H}$, the protons of benzene ring), $8.65(1 \mathrm{H}$, the proton of pteridine ring).

HSV, EDC and NHS with a molar ratio of 1: 1.5: 1.5 were mixed in $20 \mathrm{~mL}$ of formamide with stirring for $2 \mathrm{~h}$ in an ice bath, followed by the addition of $0.15 \mathrm{mmol}$ FA$\mathrm{NH}_{2}$ dissolved in $80 \mathrm{~mL}$ of DMSO under vigorous stirring. After $24 \mathrm{~h}$ at ambient temperature, the solution was purified by dialysis against DMSO/water $(3: 1-1: 1, \mathrm{v} / \mathrm{v})$ for 3 days to remove the unreacted FA- $\mathrm{NH}_{2}$, followed by dialysis against water for 2 days to remove DMSO. Eventually, the resultant FHSV polymer was collected by lyophilization.

\section{Characteristics of HSV, HCV and FHSV Polymers 'H-NMR Analysis}

The chemical structures of HA, HSV, HCV and FHSV were determined by ${ }^{1} \mathrm{H}-\mathrm{NMR}$ (BRUKER AVANCE III, Switzerland). The degree of substitution (DS) of VES, which was defined as the number of VES per 100 sugar units of HA, was calculated according to a previous report. ${ }^{43}$ In addition, the DS of FA in the FHSV polymer was analyzed via an Ultraviolet-Visible spectrophotometer at $361 \mathrm{~nm}^{44}$

\section{Critical Micelle Concentration (CMC)}

The determination of CMC of the graft polymers were undertaken using pyrene as a fluorescent probe. ${ }^{24}$ Briefly, after evaporation of $1 \mathrm{~mL}$ of $6 \times 10^{-6} \mathrm{M}$ pyrene acetone solution under a nitrogen flow, a series of block polymer solutions with concentration varying from $1 \times 10^{-3}$ to $0.5 \mathrm{mg} / \mathrm{mL}$ were added into each volumetric flask resulting in a final pyrene concentration of $6 \times 10^{-7} \mathrm{M}$, followed by sonication in a water bath for $30 \mathrm{~min}$. Thereafter, all samples were incubated at $50{ }^{\circ} \mathrm{C}$ for $1 \mathrm{~h}$ and then left at room temperature overnight. Next, the fluorescence intensity of pyrene at excitation wavelength of $333 \mathrm{~nm}$ and 338 nm was monitored with a fixed emission wavelength of $390 \mathrm{~nm}$. The CMC values were obtained by plotting the 
intensity ratio of $\mathrm{I}_{338} / \mathrm{I}_{333}$ versus the Log-transformed polymer concentration.

\section{Redox-Triggered Disassembly of Blank Micelles}

The polymer (HCV, HSV or FHSV) was dispersed in phosphate buffered saline (PBS, $\mathrm{pH} 7.4,10 \mathrm{mM}$ ) and the solution was sonicated for $15 \mathrm{~min}$ at $100 \mathrm{~W}$ in an ice bath. Then, the resulting solution was filtered through a $0.45 \mu \mathrm{m}$ microfiltration membrane to obtain the blank $\mathrm{HCV}$ micelles, blank HSV micelles or blank FHSV micelles. The size distribution of blank micelles under stimulation with various concentration of GSH was monitored via the dynamic light scattering (DLS) method. Briefly, blank HSV and FHSV micellar solution were incubated with various concentration of GSH in a thermostatic vibrating incubator at $37{ }^{\circ} \mathrm{C}$. After $24 \mathrm{~h}$, their size changes were investigated by DLS. For comparison, the change in particle size of blank HCV micellar solution in the presence of $20 \mathrm{mM}$ of GSH was also analyzed.

\section{Preparation and Characterizations of PTX-Loaded Micelles}

A dialysis method was applied to formulate drug-loaded micelles according to a reference with some modifications. ${ }^{24}$ First, $12 \mathrm{mg}$ of amphiphilic polymer (HCV, HSV or FHSV) was dissolved in $4 \mathrm{~mL}$ of water. Then, a PTX/ethanol stock solution was injected into the polymer solution $(\mathrm{PTX} /$ polymer $=20 \%, \mathrm{w} / \mathrm{w})$. After stirring for $2 \mathrm{~h}$, the organic solvent was removed by dialysis in water for $10 \mathrm{~h}$. Then, the mixture was sonicated for 15 min at $100 \mathrm{~W}$ in an ice bath. The final micellar dispersion (PTX/FHSV, PTX/HSV or PTX/HCV) was obtained by filtration through a $0.45 \mu \mathrm{m}$ microfiltration membrane.

The particle size and zeta potential were determined by DLS at $25^{\circ} \mathrm{C}$ with a scattering angle of $90^{\circ}$ in triplicate. In addition, the morphology of PTX-loaded micelles was observed by transmission electron microscopy (TEM) through a JEOL JEM 1200 TEM microscope (Tokyo, Japan) at $120 \mathrm{kV}$. To calculate the drug loading capacity (DLC) and encapsulation efficiency (EE), $0.2 \mathrm{~mL}$ PTXloaded micelles were mixed with $10 \mathrm{~mL}$ ethanol, and the solution was homogenized by ultrasonication for $20 \mathrm{~min}$. The PTX amount was analyzed using high-performance liquid chromatography (HPLC).

Power X-ray diffraction (PXRD) analysis was conducted to investigate the change in the crystalline state of PTX in the micelles. All samples were scanned from $3^{\circ}$ to $40^{\circ}(2 \theta)$ at a scanning speed of $3 \% \mathrm{~min}$ with a step size of $0.03^{\circ}$. The potential and current of X-ray tube were set to $40 \mathrm{mV}$ and $30 \mathrm{~mA}$, respectively.

\section{In vitro Drug Release}

The cumulative release of PTX from micelles was determined using a dialysis method. $1 \mathrm{~mL}$ of self-prepared Taxol or PTX-loaded micellar solution containing about $80 \mu \mathrm{g}$ PTX was immersed in $50 \mathrm{~mL}$ of $0.01 \mathrm{M}$ PBS solution ( $\mathrm{pH} 7.4)$ containing $0.5 \%(\mathrm{w} / \mathrm{v})$ Tween 80. Various concentration of GSH $(0 \mathrm{mM}$ or $10 \mathrm{mM})$ were added to the buffer solution and all samples were shaken at $100 \mathrm{rpm}$ for $60 \mathrm{~h}$ in a $37{ }^{\circ} \mathrm{C}$ thermostatic oscillator. At specific time intervals, $1 \mathrm{~mL}$ samples were collected and replaced by an equivalent volume of fresh buffer. The cumulative release of PTX was calculated by HPLC.

\section{Hemolysis Study}

The biosafety of micelles was preliminarily investigated by a hemolysis assay. Briefly, rabbit erythrocytes were collected by centrifugation and suspended in saline at $2.0 \%(\mathrm{v} / \mathrm{v})$ hematocrit. Different PTX-loaded formulations were mixed with an equivalent volume of red blood cells (RBC) suspensions, and the mixed solution was shaken at $37{ }^{\circ} \mathrm{C}$ for 3 $\mathrm{h}$. The RBC suspensions incubated with distilled water and physiological saline were set as the positive control and negative control, respectively. After $15 \mathrm{~min}$ of centrifugation at $5000 \mathrm{rpm}$, the hemolysis ratio was calculated using a UVvisible spectrophotometer at $540 \mathrm{~nm}$.

\section{In vitro Cytotoxicity Study}

The toxicity of blank carriers and PTX-loaded formulations was determined by the MTT assay. MCF-7 or NIH3T3 cell suspensions were seeded in 96-well plates and incubated for $24 \mathrm{~h}$. Then, the cells were cultured with $100 \mu \mathrm{L}$ of fresh medium containing a series of concentrations of blank carriers and PTX-loaded formulations for $48 \mathrm{~h}$. Untreated cells were used as controls. After that, the culture medium was replaced by $90 \mu \mathrm{L}$ of fresh FBS-free medium and $10 \mu \mathrm{L}$ of MTT solution $(5 \mathrm{mg} / \mathrm{mL})$, and the cells were further incubated for 4 h. Next, the supernatant was aspirated, and the generated formazan was dissolved in $150 \mu \mathrm{L}$ of DMSO. The absorbance values were recorded using a microplate reader (Varioskan Flash, Thermo Scientific, USA) at $490 \mathrm{~nm}$. Additionally, the $\mathrm{IC}_{50}$ values were determined with SPSS Statistics 22.0 (IBM, New York, USA).

To investigate the receptor-mediated effect, competitive inhibitory experiments were carried out according to the 
published reports with some modifications. ${ }^{34,45,46}$ MCF-7 cells were precultured either with free HA $(10 \mathrm{mg} / \mathrm{mL})$ or with both free HA $(10 \mathrm{mg} / \mathrm{mL})$ and free FA $(1 \mathrm{mM})$ for 1 $\mathrm{h}$ prior to treatment with PTX/FHSV micelles. The cytotoxicity was measured by MTT assay as described above.

\section{In vitro Cell Apoptosis Study}

The apoptosis rate of MCF-7 cells induced by various drugloaded formulations was quantitatively evaluated by Annexin V-FITC/PI staining method. The cells were cultured with Taxol, PTX/HCV, PTX/HSV and PTX/FHSV micelles at an equivalent PTX concentration. Untreated cells were used as controls. After $12 \mathrm{~h}$, the cells were harvested for Annexin V-FITC/PI staining. Finally, the stained cells were analyzed by flow cytometer (BD FACSAria ${ }^{\mathrm{TM}}$ III, USA).

\section{Cellular Uptake}

With respect to the evaluation of cellular uptake of micelles, fluorescence probe $\mathrm{C} 6$, as a substitute for PTX, was entrapped in polymeric micelles in line with the protocol of PTX-loaded micelles. ${ }^{47} \mathrm{C} 6$ solution prepared with reference to Taxol was used as a control. When the MCF-7 cells reached approximately $80 \%$ confluence, various C6-loaded formulations at equivalent C6 concentration of $0.5 \mu \mathrm{g} / \mathrm{mL}$ were added to incubate with cells for additional $1 \mathrm{~h}$ and 4 h. In the competitive inhibitory experiment, the cells were precultured either with free $\mathrm{HA}(10 \mathrm{mg} / \mathrm{mL})$ or with both free HA $(10 \mathrm{mg} / \mathrm{mL})$ and free FA $(1 \mathrm{mM})$ for $1 \mathrm{~h}$ to saturate the receptors expressed on cell surface. Finally, the cells were harvested by trypsinization for flow cytometry evaluation.

Furthermore, the ability of MCF-7 cells to capture micelles was qualitatively analyzed by confocal laser scanning microscopy (LSM710, CarlZeiss, Oberkochen, Germany). First, MCF-7 cells were seeded on coverslips in 12 -well plates and incubated to reach $70-90 \%$ confluence. Then, the cells were treated with fresh medium containing different C6-loaded formulations $(0.5 \mu \mathrm{g} / \mathrm{mL}$ C6). In the competitive experiments, the cellular pretreatment was similar to that for flow cytometry. After cultured for $1 \mathrm{~h}$ or $4 \mathrm{~h}$, the cells were rinsed thrice with cold PBS, fixed with $4 \%$ paraformaldehyde for $30 \mathrm{~min}$. The cell nucleus was stained with DAPI solution for $3 \mathrm{~min}$. The intracellular distribution of C6 was visualized through CLSM.

\section{Animals and Tumor Xenograft Model}

Kunming mice (female, $18 \pm 4$ g) were Liaoning Changsheng biotechnology Co. Ltd. All animal experimental procedures were approved by the Animal Ethics
Committee of Shenyang Pharmaceutical University (Shenyang, China) and were conducted according to the Principles of Laboratory Animals Care. S180 cells suspension was inoculated into the left axillae of mice to develop a subcutaneous tumor model.

\section{In vivo Biodistribution and Tumor-Targeting Ability}

The near-infrared fluorescence (NIRF) imaging method was adapted to observe the tumor-targeted potency and in vivo biodistribution of micelles. DiR was chosen to replace PTX for in vivo imaging experiments. ${ }^{47}$ When the tumor volume was increased to approximately $300-400 \mathrm{~mm}^{3}$, DiR solution prepared with reference to Taxol and various DiR-loaded micelles were injected intravenously at a dosage of $2 \mathrm{mg} \mathrm{DiR} / \mathrm{kg}(\mathrm{n}=3)$. After the mice were sacrificed at predetermined time points, NIRF images of tumor-bearing mice were obtained by Bruker MI SE imaging system (Bruker Corporation, Germany). In addition, the major tissues were dissected after $24 \mathrm{~h}$ of administration to observe the biodistribution of DiR-loaded formulations in each organ.

\section{In vivo Chemotherapy of Tumors}

The S180 tumor-bearing mice were randomly assigned to five groups $(n=5)$ when the tumor volume reached approximately $100 \mathrm{~mm}^{3}$, and each mouse was injected intravenously every other day with Taxol and PTX-loaded micelles at a dose of $10 \mathrm{mg}$ PTX/kg on days 1, 3, 5, 7, 9 and 11 , using saline injection as a control. Moreover, the tumor size and body weight of mice were monitored throughout the treatment. On day 13, tumor tissues and major organs were excised and stained with hematoxylin and eosin (H\&E) for histological analysis. In addition, terminal deoxynucleotidyl transferase dUTP nick end labeling (TUNEL) and antiCD31 staining were carried out to analyze the apoptosis and angiogenesis of tumor cells, respectively. The tumor inhibitory rate (TIR) was measured according to Equation $1:^{48}$

$$
\operatorname{TIR}(\%)=\frac{\mathrm{W}_{\text {saline }}-\mathrm{W}_{\text {sample }}}{\mathrm{W}_{\text {saline }}} \times 100
$$

where $\mathrm{W}_{\text {saline }}$ and $\mathrm{W}_{\text {sample }}$ are the average tumor weights of mice treated with saline and PTX-loaded formulations, respectively.

\section{Statistical Analysis}

All quantitative data are shown as the mean \pm standard deviation (SD). Statistical significance was determined 
with one-way analysis of variance (ANOVA) and Student's $t$-test at $95 \%$ confidence levels.

\section{Results and Discussion Synthesis and Characterizations of HCV, HSV and FHSV Polymers \\ Synthesis of HCV, HSV and FHSV Polymers}

Herein, the synthetic scheme of HCV, HSV and FHSV polymers was described in Figure S2. Initially, VES was covalently coupled to the backbone of HA via an amide reaction, utilizing disulfide bonds and alkyl bonds as the linkages, to synthesize CD44-targeted redox-sensitive HSV and redox-insensitive $\mathrm{HCV}$, respectively. Second, aminefunctionalized FA was conjugated to HSV using EDC/ NHS as catalysts, thus obtaining both CD44- and FRtargeted redox-sensitive FHSV. The chemical structures of $\mathrm{HCV}$, HSV and FHSV were verified by ${ }^{1} \mathrm{H}-\mathrm{NMR}$ in DMSO- $d_{6} / \mathrm{D}_{2} \mathrm{O}$ (Figure $2 \mathrm{~A}$ and $\mathrm{B}$ ). The signal peak at 1.94 ppm was assigned to the $\mathrm{N}$-acetyl groups of HA, and the broad multiplet between $3.16 \mathrm{ppm}$ and $4.44 \mathrm{ppm}$ belonged to the methylene protons in the sugar rings of HA. In the spectrum of HSV, the characteristic peaks at $2.83 \mathrm{ppm}$ and $0.78 \mathrm{ppm}$ were attributed to the methylene protons of CYS $\left(4 \mathrm{H}, 2 \mathrm{CH}_{2} \mathrm{~S}\right)$ and the methyl protons of VES $\left(12 \mathrm{H}, 4 \mathrm{CH}_{3}\right)$, respectively, suggesting the successful preparation of HSV polymer. Similarly, the successful conjugation of VES-EDA onto the backbone of HA was confirmed by the appearance of peaks at $0.83 \mathrm{ppm}$ and 2.89 ppm, which belonged to the methyl protons of VES $(12 \mathrm{H}$, $\left.4 \mathrm{CH}_{3}\right)$ and the methylene protons of $\operatorname{EDA}\left(4 \mathrm{H}, 2 \mathrm{CH}_{2} \mathrm{NH}\right)$. Compared to the spectra of $\mathrm{HSV}$ and $\mathrm{HCV}$, the newly emerged signal peaks at $6.76 \mathrm{ppm}, 7.65 \mathrm{ppm}$ and 8.74 ppm in the ${ }^{1} \mathrm{H}-\mathrm{NMR}$ spectrum of FHSV were ascribed to the protons of benzene rings and pteridine rings of FA, suggesting the successful conjugation of FA to HSV.

The DS of VES for HCV, HSV and FHSV polymers were quantitatively determined by the ratio of integration area of the methyl protons of VES $(\sim 0.78 \mathrm{ppm})$ to the $\mathrm{N}$-acetyl groups of HA (1.94 ppm), which were $18.06 \pm$ $1.76 \%, 16.64 \pm 2.15 \%$ and $16.05 \pm 1.92 \%$, respectively. In addition, the DS of FA for FHSV measured by UV-vis spectrophotometry was $8.52 \pm 1.24 \%$.

\section{Critical Micelle Concentration (CMC)}

The CMC values of amphiphilic polymers were determined by fluorescence spectroscopy. As shown in Figure $2 \mathrm{C}$, the CMC values of HCV, HSV and FHSV were 24.56 $\pm 2.12 \mathrm{mg} / \mathrm{L}, 18.95 \pm 1.23 \mathrm{mg} / \mathrm{L}$ and $15.78 \pm 1.08 \mathrm{mg} / \mathrm{L}$, respectively. The CMC of the well-designed polymers were significantly lower than those of low molecular weight surfactants, such as Pluronic F127 (0.24 mg/ $\mathrm{mL}){ }^{49}$ Moreover, the relatively low CMC was beneficial for maintaining the stability of polymeric micelles in blood circulation before reaching the target sites. ${ }^{26}$

\section{Redox-Triggered Disassembly of Blank Micelles}

To illustrate the redox-sensitive breakage of disulfide bonds in the micelles, the size distribution of blank HSV and FHSV micelles upon exposure to various concentration of GSH over time was measured with blank HCV micelles as the control. As apparent from Figure 3, the particle size of all blank micelles exhibited no obvious change after incubation in PBS for $24 \mathrm{~h}$. In contrast, the presence of $10 \mathrm{mM} \mathrm{GSH} \mathrm{led}$ to an increase in the particle size of FHSV micelles and HSV micelles exhibiting the multipeak phenomenon in distribution. Furthermore, significant size growth and a broader size distribution were observed under the condition of $20 \mathrm{mM} \mathrm{GSH}$, suggesting the reduction-triggered breakage of disulfide bonds would rely on the amount of the surrounding GSH. ${ }^{24}$ However, simulation of the redox potential of extracellular compartment by $10 \mu \mathrm{M}$ GSH caused negligible size variation in FHSV and HSV micelles under otherwise unchanged conditions. As a control, the particle size of redox-insensitive $\mathrm{HCV}$ micelles was almost constant even after exposure to $20 \mathrm{mM}$ GSH. Therefore, these results confirmed that redoxsensitive FHSV micelles and HSV micelles could be stable under normal physiological conditions but rapidly disassemble under GSH-rich environment, such as in the cytoplasm of tumor cells, which excellently resolved the contradiction between extracellular stability and intracellular release.

\section{Preparation and Characterizations of PTX-Loaded Micelles}

A simple dialysis method was applied to encapsulate hydrophobic PTX into the hydrophobic cores of polymeric micelles. Table 1 summarizes a variety of properties of blank micelles and drug-loaded micelles. The hydrodynamic diameters of PTX/HCV micelles, PTX/HSV micelles and PTX/FHSV micelles were $171.9 \pm 1.3 \mathrm{~nm}, 157.2 \pm 1.6 \mathrm{~nm}$, and $148.8 \pm 1.4 \mathrm{~nm}$, respectively, which were larger than those of corresponding blank micelles. This phenomenon might be because the drug-loading process resulted in a more compact nanostructure through hydrophobic interactions between PTX and the hydrophobic inner cores of polymeric micelles. ${ }^{50}$ Furthermore, the polydispersity index (PDI) of all drug-loaded micelles was in a narrow range of 
A
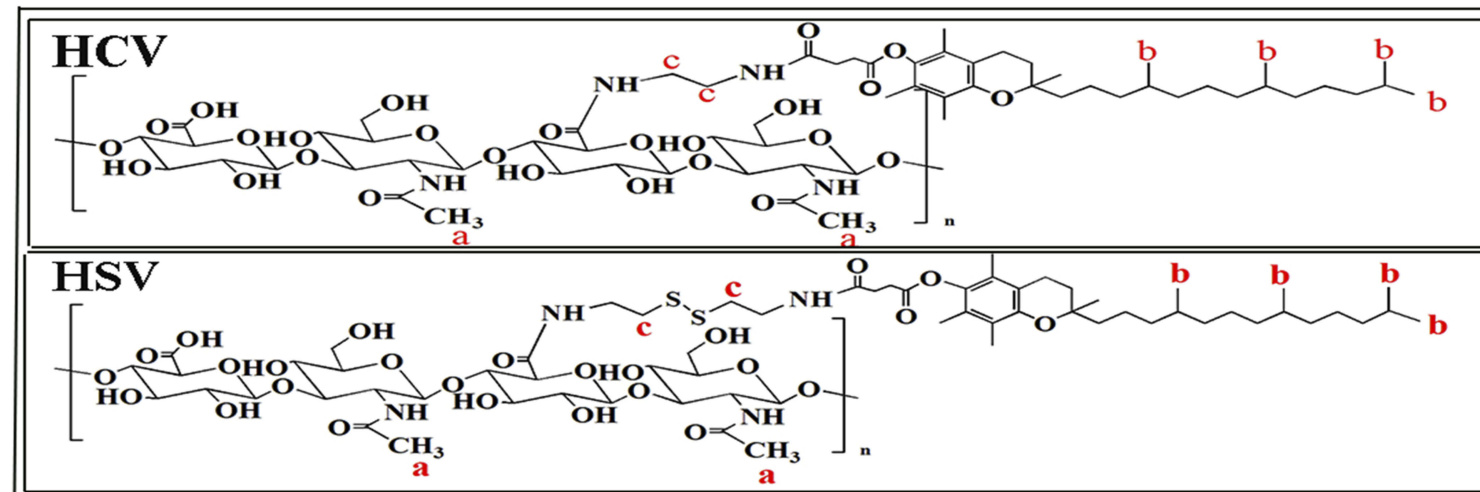

FHSV

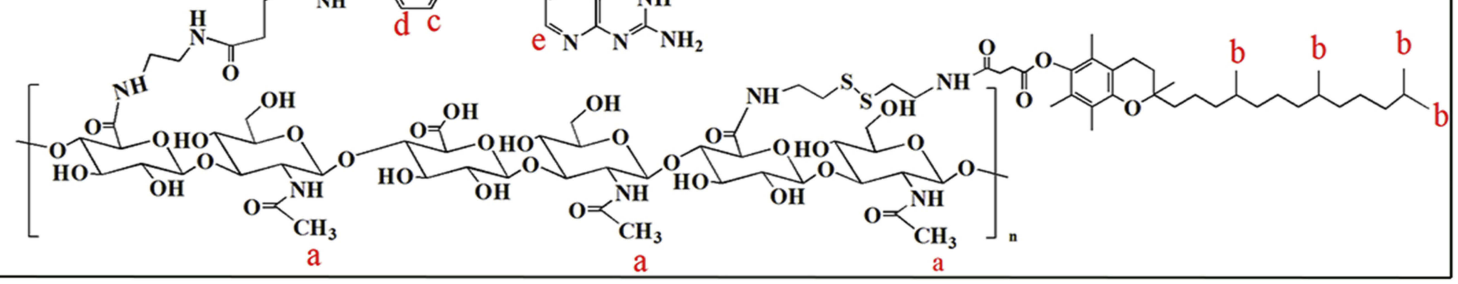

B

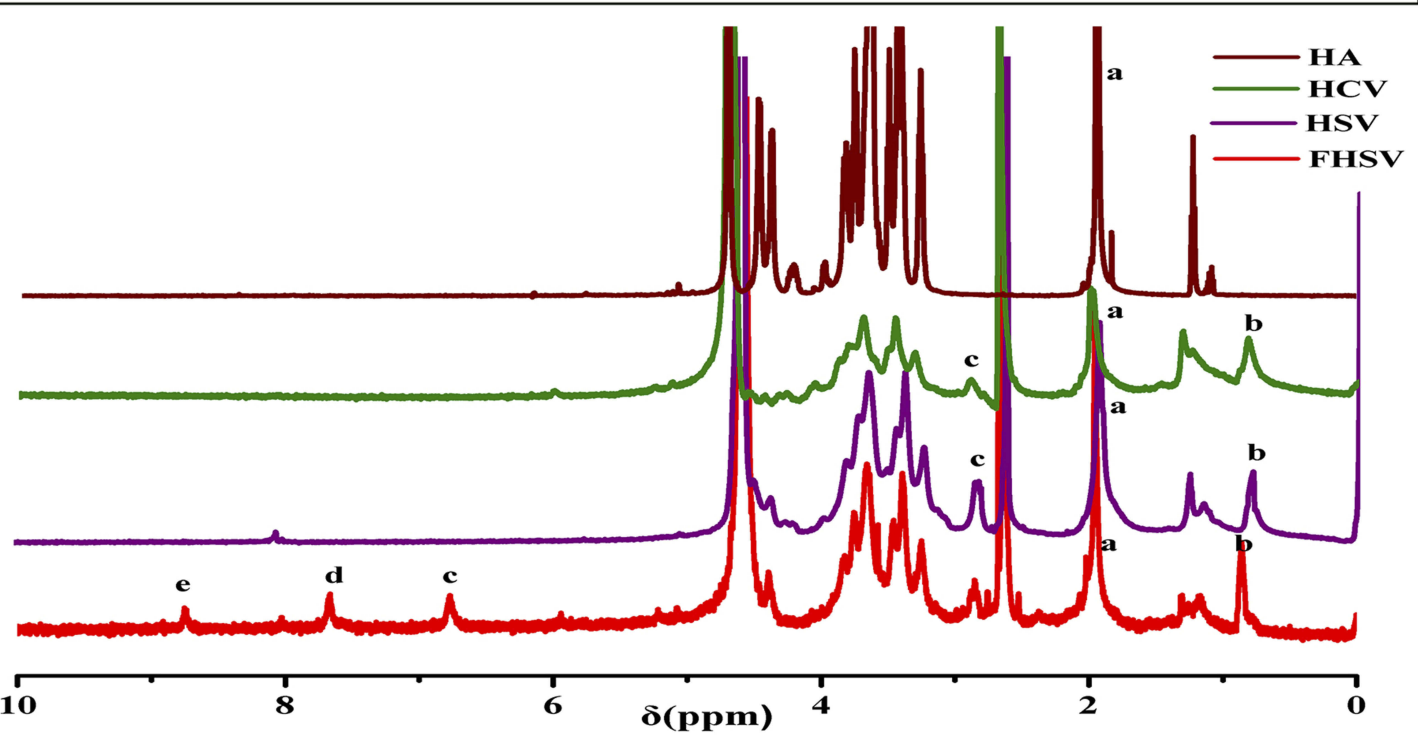

C
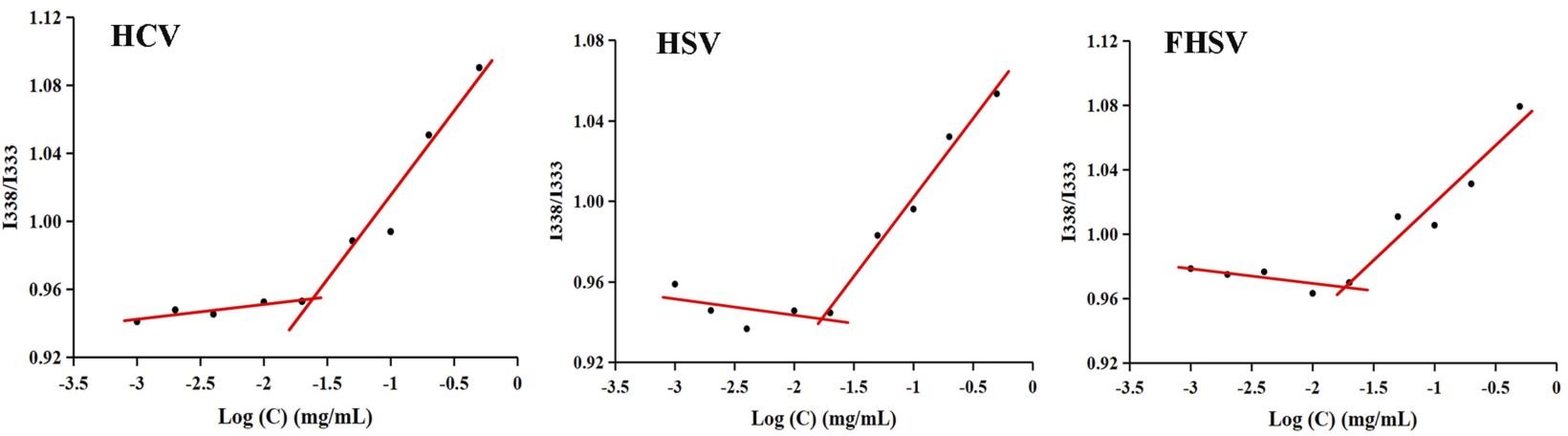

Figure 2 (A) Chemical structures of HCV, HSV and FHSV polymers. (B) ' $\mathrm{H}-\mathrm{NMR}$ spectra of $\mathrm{HA}$ in $\mathrm{D}_{2} \mathrm{O}, \mathrm{HCV}, \mathrm{HSV}$ and FHSV polymers in DMSO-d $/ \mathrm{d}_{2} \mathrm{O}$ (v/v, I:I). (C) The CMC of HCV, HSV and FHSV polymers. 

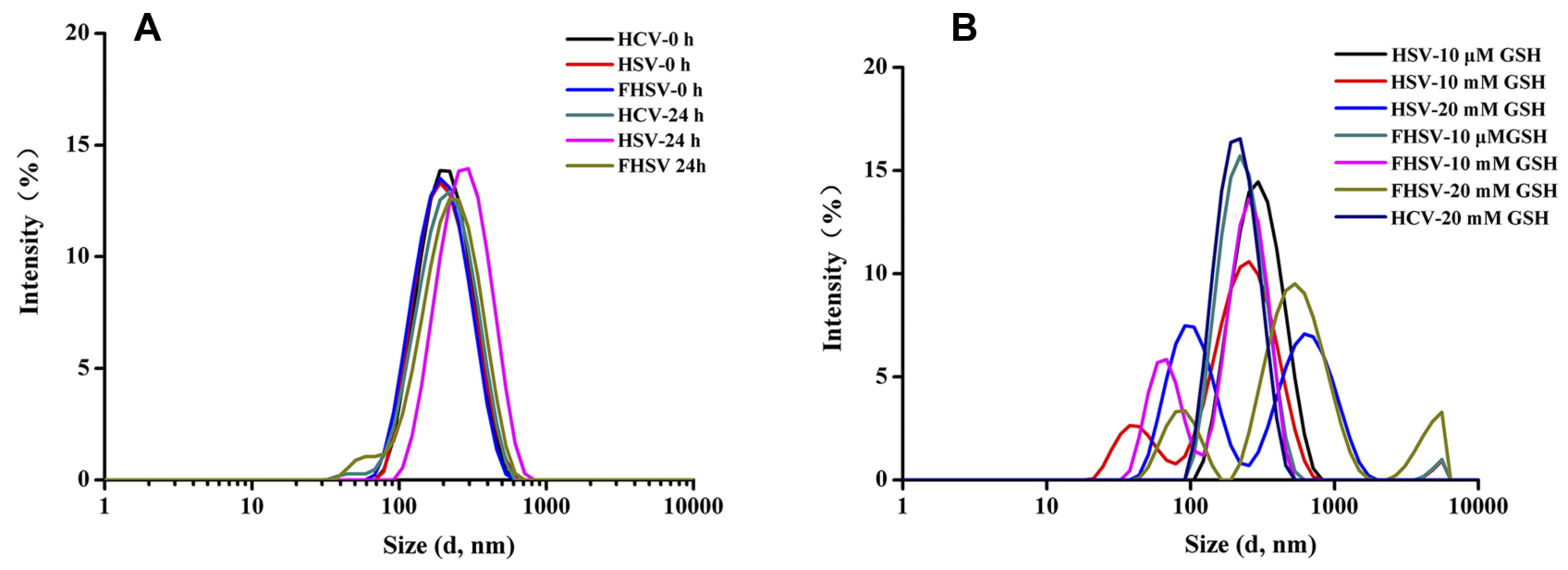

Figure 3 Size distribution of blank micelles after incubation (A) in PBS ( $10 \mathrm{mM}, \mathrm{pH} 7.4)$ for $0 \mathrm{~h}$ and $24 \mathrm{~h}$ (B) in PBS (10 mM, pH 7.4) with $10 \mu \mathrm{M}, 10 \mathrm{mM}$ and $20 \mathrm{mM}$ GSH for $24 \mathrm{~h}$.

0.071 to 0.130 , indicating a uniform particle size distribution. The morphology was further detected by TEM (Figure 4A). The TEM images all displayed uniform, near-spherical structures and narrow size distributions. However, the average size of TEM measurement was smaller than that of DLS measurement, which might be attributed to the removal of water from micelles during TEM sample preparation leading to the shrinkage of hydrophilic shell of micelles. ${ }^{51}$ The zeta potential of all drug-loaded micelles was negative because of the existence of free carboxyl groups on the backbone of HA, which helped to reduce their binding to serum proteins and prolong the in vivo circulation time of the drug. More notably, PTX/FHSV micelles had a higher potential $(-22.1 \pm 0.2$ $\mathrm{mV})$ than PTX/HSV micelles $(-36.3 \pm 0.4 \mathrm{mV})$ and PTX/ HCV micelles $(-34.1 \pm 0.2 \mathrm{mV})$. This might be caused by the reduction in the number of free carboxyl groups in FHSV polymer after connecting the carboxyl groups of HA with the primary amines of FA- $\mathrm{NH}_{2}$. As shown in Table 1, due to the similar DS of VES, the DLC and EE of the three drug-loaded micelles were comparable, and were in the range of 11.28 $12.51 \%$ and $63.58-71.49 \%$, respectively. Moreover, modification of FA has a small influence on the DLL and EE.

PXRD analysis was carried out to verify the existence state of PTX in the PTX-loaded micelles. As shown in Figure S3, PTX exhibited several intense peaks at $2 \theta$ values of $5.64^{\circ}, 9.12^{\circ}, 10.11^{\circ}, 11.16^{\circ}$ and $12.66^{\circ}$ and numerous small peaks in the range of $15.67^{\circ}$ to $29.97^{\circ} .52$ These characteristic peaks appeared in the XRD pattern of the physical mixture of PTX and FHSV polymer but disappeared in the XRD spectra of PTX-loaded micelles. These observations indicated that PTX was distributed in the micelles in amorphous or molecular state.

\section{In vitro Drug Release}

Evidence suggests that tumor cells have a higher level of GSH than normal cells, which is beneficial to cancer therapy. ${ }^{38}$ Therefore, the cumulative release of micelles was measured in the presence or absence of GSH. As shown in Figure 4B,

Table I Physicochemical Characteristics of PTX-Loaded Micelles $(n=3)$

\begin{tabular}{|l|l|l|l|l|l|l|l|}
\hline Sample & $\begin{array}{l}\text { Particle Size } \\
(\mathbf{d}, \mathbf{n m})\end{array}$ & PDI & Zeta Potential (mV) & EE (\%) & DLC (wt\%) & DS (\%) & CMC (mg/L) \\
\hline HCV & $179.1 \pm 2.6$ & $0.122 \pm 0.011$ & $-32.1 \pm 1.2$ & - & - & $18.06 \pm 1.76$ & $24.56 \pm 2.12$ \\
HSV & $168.4 \pm 3.0$ & $0.165 \pm 0.020$ & $-34.4 \pm 0.6$ & - & - & $16.64 \pm 2.15$ & $18.95 \pm 1.23$ \\
FHSV & $154.5 \pm 2.9$ & $0.279 \pm 0.011$ & $-22.7 \pm 1.4$ & - & - & $16.05 \pm 1.92$ & $15.78 \pm 1.08$ \\
& & & & & $(8.52 \pm 1.24)^{\mathrm{a}}$ & \\
PTX/HCV & $171.9 \pm 1.3$ & $0.071 \pm 0.035$ & $-34.1 \pm 0.2$ & $66.84 \pm 1.05$ & $11.79 \pm 0.16$ & - & - \\
PTX/HSV & $157.2 \pm 1.6$ & $0.116 \pm 0.006$ & $-36.3 \pm 0.4$ & $71.49 \pm 2.21$ & $12.51 \pm 0.34$ & - & - \\
PTX/FHSV & $148.8 \pm 1.4$ & $0.130 \pm 0.006$ & $-22.1 \pm 0.2$ & $63.58 \pm 1.32$ & $11.28 \pm 0.25$ & - & - \\
\hline
\end{tabular}

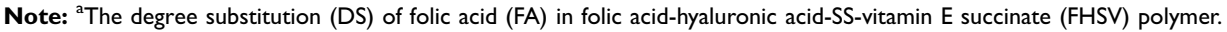



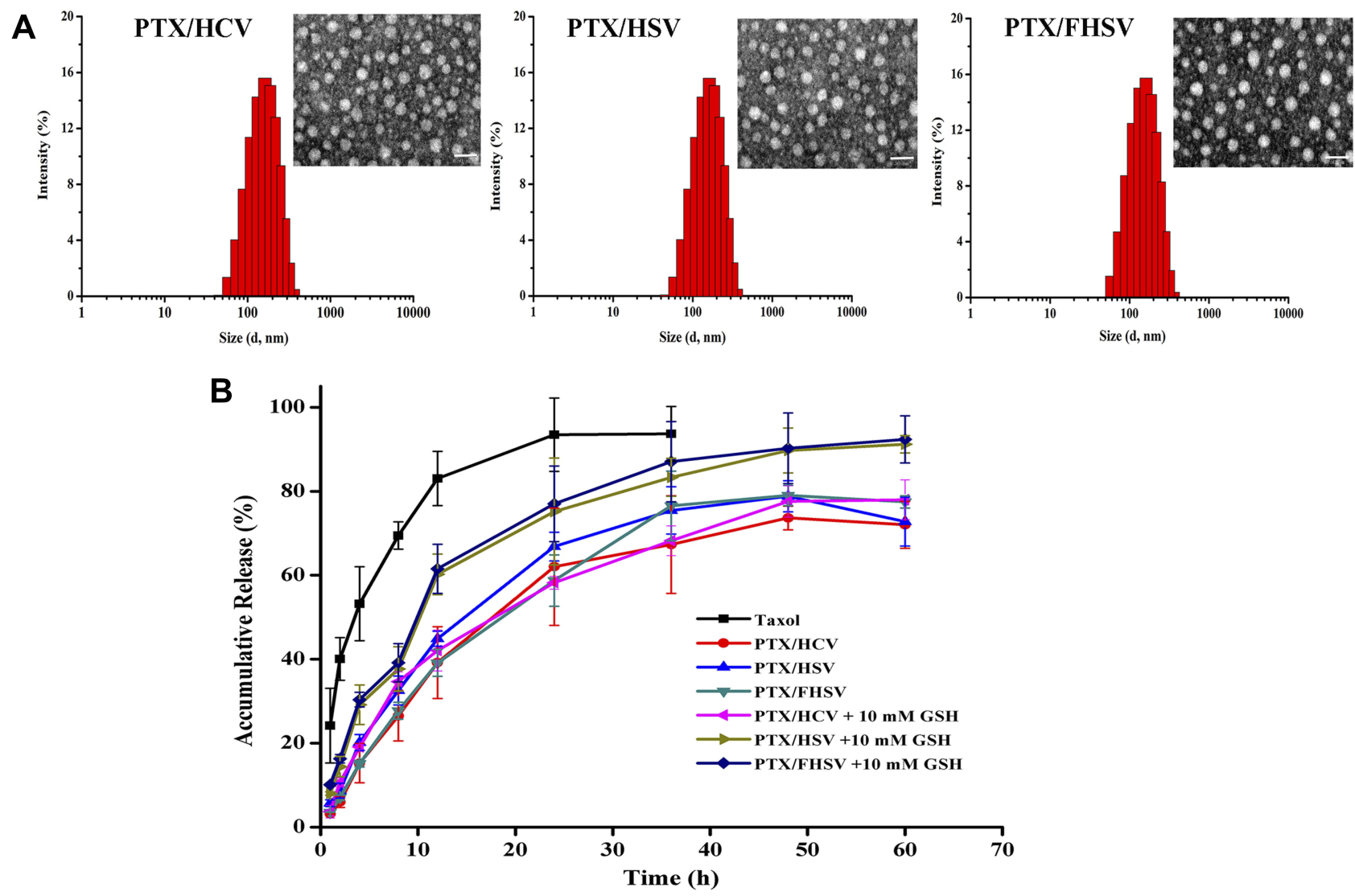

Figure 4 (A) Size distribution and TEM images of PTX-loaded micelles. Scale bar represents $50 \mu \mathrm{m}$. (B) In vitro drug release of Taxol and PTX-loaded micelles in PBS (I0 $\mathrm{mM}, \mathrm{pH}$ 7.4) with or without $10 \mathrm{mM} \mathrm{GSH}$. Data are presented as mean $\pm \mathrm{SD}(\mathrm{n}=3)$.

Taxol showed a rapid release of PTX with $83.26 \%$ at $\mathrm{pH} 7.4$ within $12 \mathrm{~h}$. In comparison, all PTX-loaded micelles showed slow and inefficient PTX release at $\mathrm{pH} 7.4$, with only $37.93 \%$, $46.47 \%$ and $40.96 \%$ of PTX released from PTX/HCV micelles, PTX/HSV micelles and PTX/FHSV micelles within $12 \mathrm{~h}$, respectively. In addition, the cumulative release of all PTX-loaded micelles only reached $72.01-76.80 \%$ within 60 h. However, in the same buffer solution with $10 \mathrm{mM} \mathrm{GSH}$, the release rate of PTX from PTX/HSV micelles and PTX/FHSV micelles was drastically accelerated, and the cumulative drug release reached $65.21 \%$ and $69.58 \%$ within $12 \mathrm{~h}$, and $91.02 \%$ and $92.35 \%$ within $60 \mathrm{~h}$, respectively. As expected, no obvious release acceleration was observed in PTX/HCV micelles in the presence of $10 \mathrm{mM}$ GSH. These signified that the redoxsensitive micelles could be rapidly disassembled in the high concentration of GSH to achieve fast drug release and enhance their antitumor efficacy.

\section{Hemolysis Study}

Blood biocompatibility is a crucial issue in clinical administration, particularly in intravenous administration, so a hemolysis study of PTX-loaded micelles was conducted. Figure S4 demonstrates that none of the micellar solution caused significant hemolysis of rabbit erythrocytes, and the hemolysis ratio was far below the acceptable range ( $<5 \%$ ). Additionally, when the PTX concentration was $100 \mu \mathrm{g} / \mathrm{mL}$ and $200 \mu \mathrm{g} / \mathrm{mL}$, the hemolytic toxicity of PTX-loaded micelles was significantly lower than that of Taxol ( $p<0.05$ ), indicating their good biocompatibility for intravenous injection.

\section{In vitro Cytotoxicity Study}

To preliminarily evaluate the pharmaceutical application of micelles, the toxicity of blank micelles and drug-loaded micelles against NIH3T3 cells and MCF-7 cells were estimated by the MTT assay. Cremophor EL and Taxol were considered controls. As shown in Figure S5, compared to Cremophor EL, the cell viability of NIH3T3 cells treated with blank micelles was above 95\%, even at high concentrations, indicating their biosafety to normal cells. For MCF-7 cells, the blank micelles showed no toxicity when the concentration of blank micelles was in the range 
of 5-200 $\mu \mathrm{g} / \mathrm{mL}$. However, at high concentration, the survival rates of MCF-7 cells were appreciably reduced and were $86.02 \% \pm 2.69 \%, 81.07 \% \pm 4.58 \%$ and $77.72 \% \pm$ $4.75 \%$ for blank HCV micelles, blank HSV micelles and blank FHSV micelles, respectively. Moreover, the redoxsensitive blank HSV micelles and blank FHSV micelles showed higher cytotoxicity than redox-insensitive blank $\mathrm{HCV}$ micelles, indicating that the dissociation of polymers played an indirect effect on cell viability. According to the literature, VES could decrease the mitochondrial membrane of tumor cells and accelerate cell apoptosis, but had less toxicity or non-toxicity to normal cells. ${ }^{40}$ Therefore, compared to blank HCV micelles, the rapidly disaggregation of blank HSV micelles and FHSV micelles in high concentration GSH produced more VES to killing tumor cells.

The cytotoxicity of PTX-loaded formulations in NIH3T3 cells and MCF-7 cells was dose-dependent (Figure 5A-C). In MCF-7 cells, the half maximum inhibition concentration $\left(\mathrm{IC}_{50}\right)$ values of Taxol, PTX/ $\mathrm{HCV}$ micelles, PTX/HSV micelles and PTX/FHSV micelles were $0.885 \pm 0.071 \mu \mathrm{g} / \mathrm{mL}, 0.818 \pm 0.036 \mu \mathrm{g} /$ $\mathrm{mL}, 0.357 \pm 0.079 \mu \mathrm{g} / \mathrm{mL}$ and $0.200 \pm 0.027 \mu \mathrm{g} / \mathrm{mL}$, respectively. Compared to Taxol and PTX/HCV micelles, PTX/HSV micelles and PTX/FHSV micelles exhibited a statistically significant $(p<0.001)$ increase of cytostatic activity. Importantly, PTX/FHSV micelles demonstrated the best toxicity against MCF-7 cells. It was previously reported that MCF-7 cells exhibited high CD44 receptor and FR expression. ${ }^{53}$ So, the enhanced cytotoxicity of PTX/FHSV micelles might be attributed to the enhanced cellular uptake mediated by the binding of HA to CD44 receptor and FA to FR. Moreover, according to the results of in vitro drug release, PTX/FHSV micelles could rapidly release PTX in the GSH-rich tumor environment, thus leading to fast transport of PTX into the nucleus to restrain the cell proliferation. NIH3T3 cells which expressed a low level of $\mathrm{CD} 44$ receptor ${ }^{54}$ and $\mathrm{FR}^{55}$ were chosen to
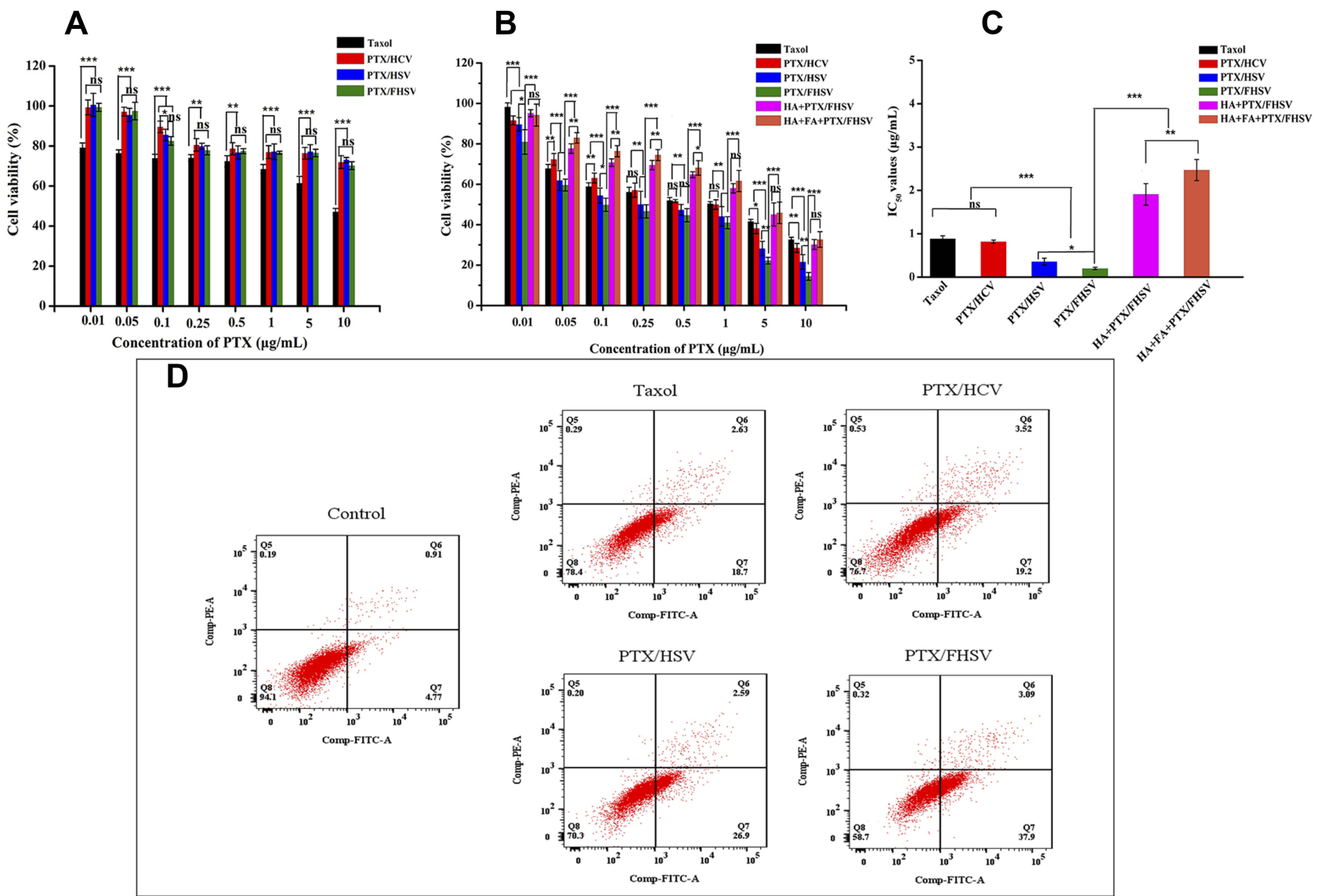

Figure 5 Cell viability of (A) NIH3T3 cells and (B) MCF-7 cells treated for $48 \mathrm{~h}$ with Taxol and PTX-loaded micelles. In the competitive inhibition experiment, the MCF-7 cells were precultured either with free $\mathrm{HA}(10 \mathrm{mg} / \mathrm{mL})$ or with both free $\mathrm{HA}(10 \mathrm{mg} / \mathrm{mL})$ and free FA $(1 \mathrm{mM})$ for I h prior to treatment with PTX/FHSV micelles. (C) The $I_{50}$ values of PTX-loaded formulations against MCF-7 cells. Data are presented as mean \pm SD $(n=6)$. * $p<0.05$; ** $p<0.0$ I; *** $p<0.00$ I; ns, $p>0.05$. (D) Apoptotisis of MCF-7 cells treated for $12 \mathrm{~h}$ with Taxol and PTX-loaded micelles. 
evaluate the safety of PTX-loaded micelles. It was obvious that all the PTX-loaded formulations revealed lower cytotoxicity than their counterparts in MCF-7 cells, indicating their high selectivity to carcinomatous cell lines. In contrast, Taxol could be readily internalized into NIH3T3 cells by passive diffusion, thus killing cells.

To ascertain the effect of receptor-mediated endocytosis on the enhanced cytotoxicity of PTX/FHSV micelles, competitive inhibitory experiments were conducted. Free HA and free FA were used as receptor inhibitors to competitively saturate the CD44 receptor and FR on the surface of MCF-7 cells, respectively. As shown in Figure 5B and $\mathrm{C}$, shows that the cell viability of MCF-7 cells in the receptor inhibitor groups (HA+PTX/FHSV group or HA + FA+PTX/FHSV group) was drastically increased. Additionally, the $\mathrm{IC}_{50}$ value of $\mathrm{HA}+\mathrm{FA}+\mathrm{PTX} / \mathrm{FHSV}$ group was about $2.470 \pm 0.244 \mu \mathrm{g} / \mathrm{mL}$, which was extremely higher than $1.910 \pm 0.249 \mu \mathrm{g} / \mathrm{mL}$ of $\mathrm{HA}+\mathrm{PTX} / \mathrm{FHSV}$ group $(p<0.01)$. Therefore, these results underlined that the interaction of HA-CD44 binding and FA-FR binding played an active role in the therapy efficacy of PTX/FHSV micelles.

\section{In vitro Cell Apoptosis Study}

Annexin V-FITC/PI staining method was used to detect the apoptosis of MCF-7 cells induced by different PTXloaded formulations. As shown in Figure 5D, all the PTX formulations produced significantly stronger apoptosisinducing ability than the untreated control group $(p<$ 0.01). Moreover, a total apoptotic rate (early apoptosis cells plus late apoptotic cells) of MCF-7 cells incubated with PTX/FHSV micelles was $40.99 \%$, which was much higher than the $29.49 \%$ of PTX/HSV micelles, $22.72 \%$ of PTX/HCV micelles and $21.33 \%$ of Taxol. These results were consistent with the findings of MTT assay, indicating that our designed PTX/FHSV micelles would effectively promote the apoptosis of tumor cells and improve the antitumor efficacy of PTX.

\section{Cellular Uptake}

The cellular uptake of PTX-load micelles was studied in MCF-7 cells via flow cytometry and CLSM. To better evaluate the uptake behavior of PTX-loaded micelles, the fluorescent probe $\mathrm{C} 6$ was selected as a substitute for PTX. Figure 6 suggests that the cellular uptake of different C6 formulations occurred in a time-dependent manner. As expected, C6-loaded micelles exhibited significantly stronger mean fluorescent intensity (MFI) than C6 solution in
MCF-7 cells $(p<0.01)$, which might be due to the enhanced endocytosis mediated by specific ligandreceptor interaction. In addition, after $4 \mathrm{~h}$ of incubation, the MFI of cells incubated with C6/FHSV micelles was 1.22 -fold and 1.30-fold of those incubated with $\mathrm{C} 6 / \mathrm{HSV}$ micelles and $\mathrm{C} 6 / \mathrm{HCV}$ micelles, suggesting the high intracellular internalization capacity of C6/FHSV. The findings from the CLSM analysis were consistent with the results of flow cytometry, and the strongest green fluorescence signal was appeared in MCF-7 cells treated with C6/FHSV micelles.

To verify that the FHSV micelles were selectively internalized by receptor-mediated endocytosis pathway into tumor cells, competitive experiments were conducted. Figure 6 shows that the C6 fluorescence intensity in MCF-7 cells was dramatically reduced by pretreating the cells with receptor inhibitors prior to incubating with C6/FHSV micelles. In addition, the pretreatment of MCF-7 cells with free HA and FA exhibited the weakest fluorescence intensity, indicating that C6/FHSV micelles were predominantly trafficked into the cells via dual receptor-mediated endocytosis pathway. Moreover, these observations of cellular uptake gave a good explanation to the results of MTT studies, suggesting that our well-designed FHSV micelles could selectively deliver antitumor drugs to tumor cells via specific receptor-mediated endocytosis and effectively kill tumor cells.

\section{In vivo Biodistribution and Tumor-Targeting Assays}

The tumor targetability of micelles was estimated via a noninvasive NIR imaging system. The time-dependent biodistribution of DiR-loaded formulations is displayed in Figure 7A. The fluorescence signal of the DiR solution was rapidly distributed throughout the whole body of mice $1 \mathrm{~h}$ after injection. The fluorescence signal weakened sharply after $12 \mathrm{~h}$ of administration and remained faintly visible at $24 \mathrm{~h}$, indicating its rapid elimination from the blood. In contrast, the fluorescence signal of DiR-loaded micelles exhibited stronger tumor accumulation and remained strong even at $24 \mathrm{~h}$ postinjection. Therefore, it demonstrated that the hydrophilic HA shell of DiR-loaded micelles could not only prolong the blood circulation time of micelles but also increase the tumor aggregation of micelles by virtue of the EPR effect and receptormediated targeting effect. In addition, during the entire imaging test, the DiR/FHSV micelles displayed the strongest fluorescence signal accumulation at the tumor sites, 

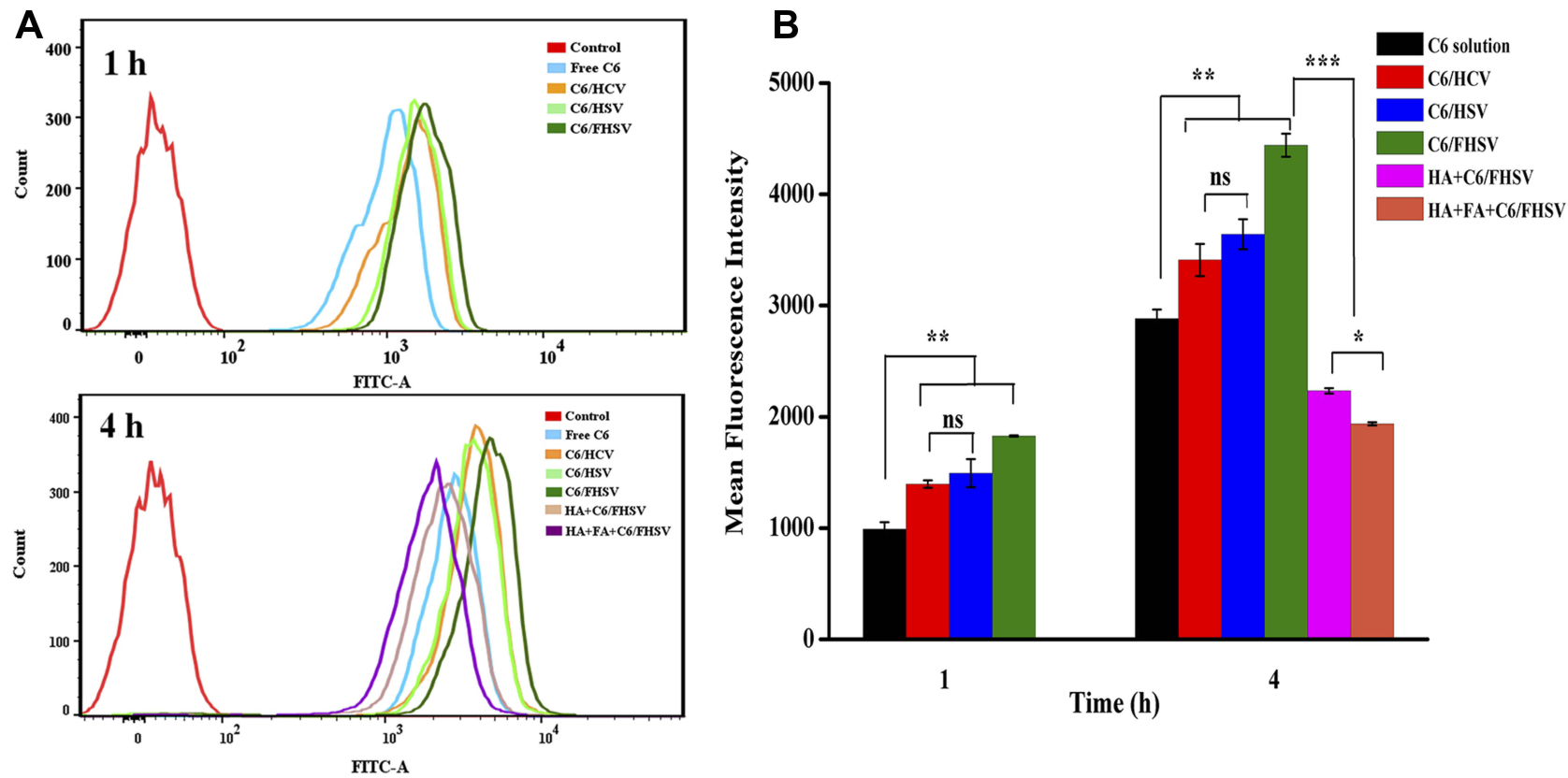

\section{C}
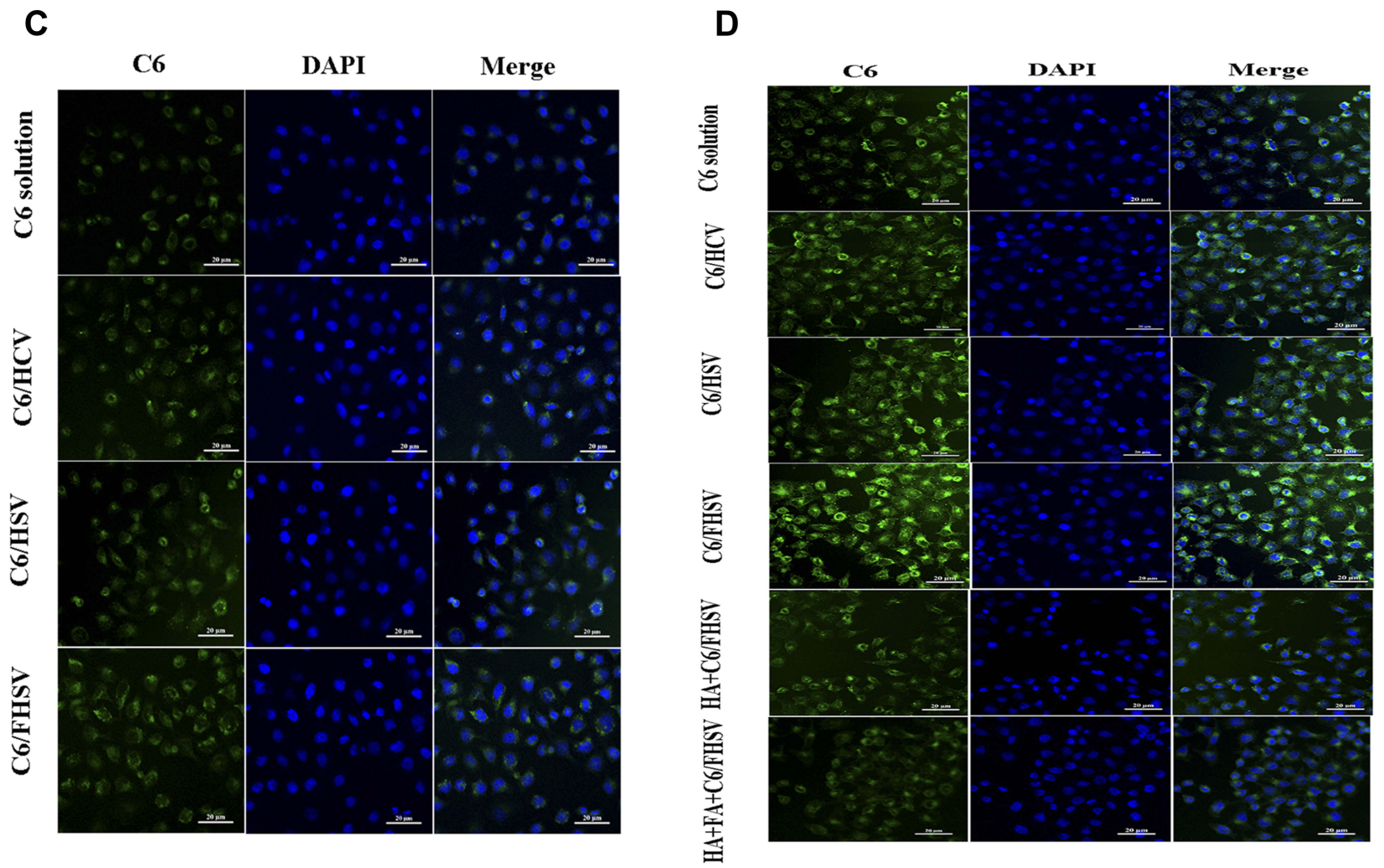

Figure 6 Time-dependent cellular uptake of C6-loaded formulations in MCF-7 cells. (A) Flow cytometry profiles and (B) quantification of MFI of MCF-7 cells following I $\mathrm{h}$ and $4 \mathrm{~h}$ incubation with C6-loaded formulations. Data are presented as mean \pm SD. $(n=3)$. ${ }^{*} p<0.05 ; * *_{p}<0.01$; $* * * p<0.001 ; n s, p>0.05$. CLSM images of MCF-7 cells incubated for (C) I h and (D) $4 \mathrm{~h}$ with C6-loaded formulations. The competitive inhibition experiments were performed by treating MCF-7 cells either with free HA ( $10 \mathrm{mg} / \mathrm{l}$ $\mathrm{mL})$ or with free $\mathrm{HA}(10 \mathrm{mg} / \mathrm{mL})$ and FA $(1 \mathrm{mM})$ before adding C6/FHSV micelles.

followed by DiR/HSV micelles, DiR/HCV micelles and the DiR solution. This suggested that the FA functionalization of DiR/FHSV micelles also had a crucial influence on the tumor-specific recognition.
The fluorescence imaging of the excised major organs after $24 \mathrm{~h}$ of administration was further studied. As shown in Figure 7B, the DiR solution group showed negligible fluorescence signals in the tumor, while strong accumulation was 

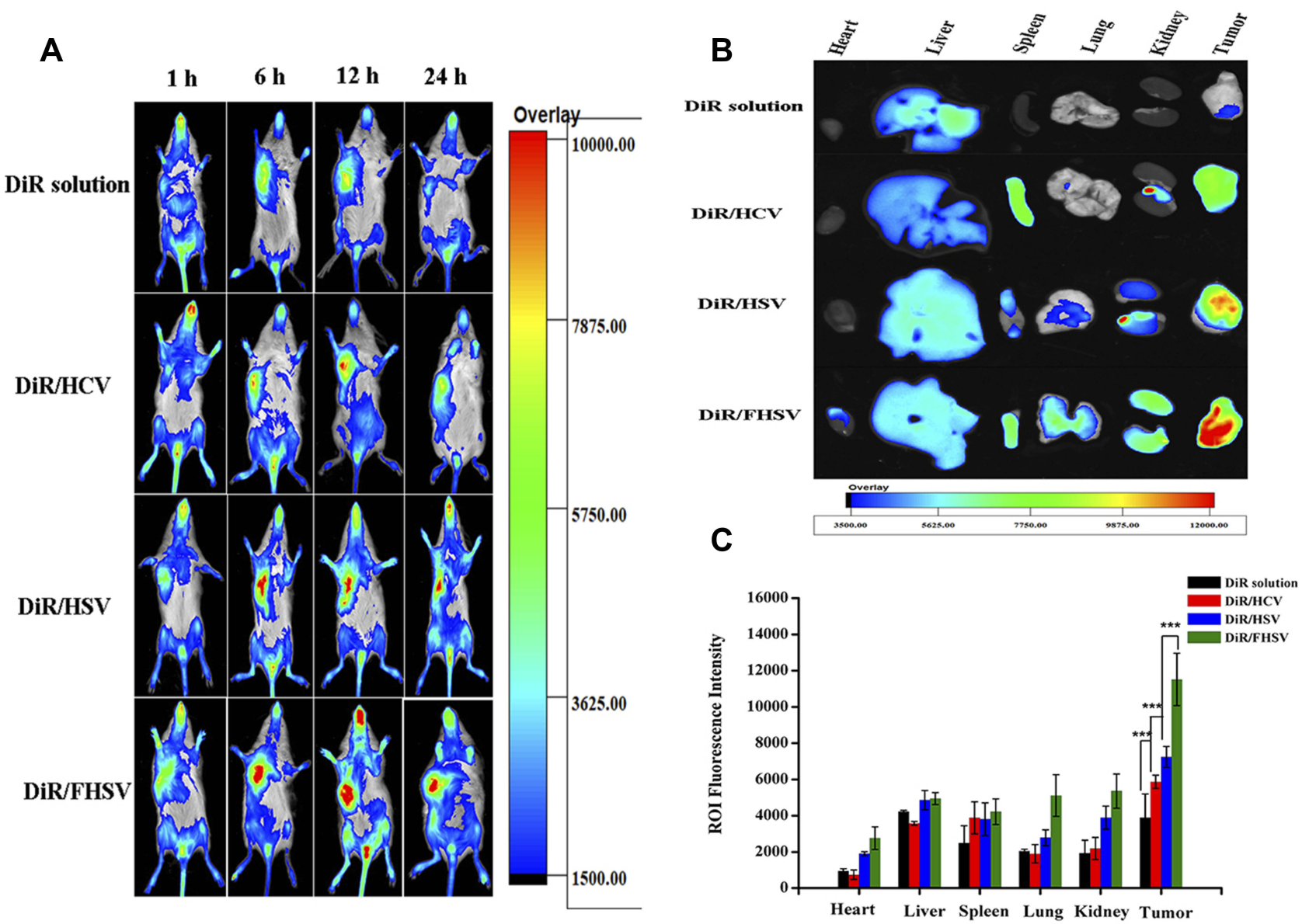

Figure 7 Bio-distribution of DiR solution and DiR-loaded micelles. (A) In vivo imaging of DiR solution and DiR-loaded micelles in SI80 tumor-bearing mice at I h, 6 h, 12 $\mathrm{h}$ and $24 \mathrm{~h}$ postinjection, respectively. (B) Ex vivo fluorescence imaging of excised organs and tumors at $24 \mathrm{~h}$ postinjection. (C) Quantitative results of major organs and tumors accumulation at $24 \mathrm{~h}$ post injection $(\mathrm{n}=3)$. $* * * \mathrm{p}<0.00 \mathrm{I}$.

observed in the liver. In comparison, DiR-loaded micelles exhibited considerable fluorescence signal in the tumor, liver and spleen. Importantly, the fluorescence signal in tumor tissues was dramatically stronger than that in normal organs. Such an increase in the liver and spleen was likely ascribed to the interaction of HA with HARE receptors on liver sinusoidal endothelial cells and the nonspecific uptake by phagocytic cells of reticuloendothelial system (RES). ${ }^{56}$ Moreover, FHSV micelles showed a significantly higher distribution in the kidney and lung than HSV micelles and HCV micelles, which was likely due to the prolonged blood circulation time of FHSV micelles after modification with FA, resulting in a slower excretion from the body. It was undeniable that the binding of FA to the FR expressed on the proximal kidney tubules also provided an explanation for the increased kidney accumulation. ${ }^{57}$ Among the three micelles tested, DiR/FHSV micelles showed the greatest amount of tumor accumulation. Quantitative region-of-intensity (ROI) analysis revealed that the fluorescence intensity of DiR/
FHSV micelles in tumor tissue was 1.59-fold, 1.96-fold and 2.96-fold stronger than that of DiR/HSV micelles, $\mathrm{DiR} / \mathrm{HCV}$ micelles and DiR solution, respectively (Figure 7C). These results demonstrated that dual receptor-targeted FHSV micelles exhibited high tumor accumulation and retention. The excellent antitumor efficacy of FHSV micelles could be due to the following reasons: (1) EPR effect, (2) prolonged blood circulation time, (3) enhanced cellular internalization by dual receptor-mediated endocytosis.

\section{In vivo Chemotherapy of Tumors}

To assess the therapeutic effect of drug-loaded formulations, Taxol and different PTX-loaded micelles (equivalent to $10 \mathrm{mg}$ PTX $/ \mathrm{kg}$ ) were injected intravenously into the S180 subcutaneous tumor model every other day for six times, while saline acted as a control. In addition, tumor volume and body weight were simultaneously monitored. Figure $8 \mathrm{~A}$ depicts that the tumor growth was time-related, and the tumors in all drug-treated groups exhibited substantial 

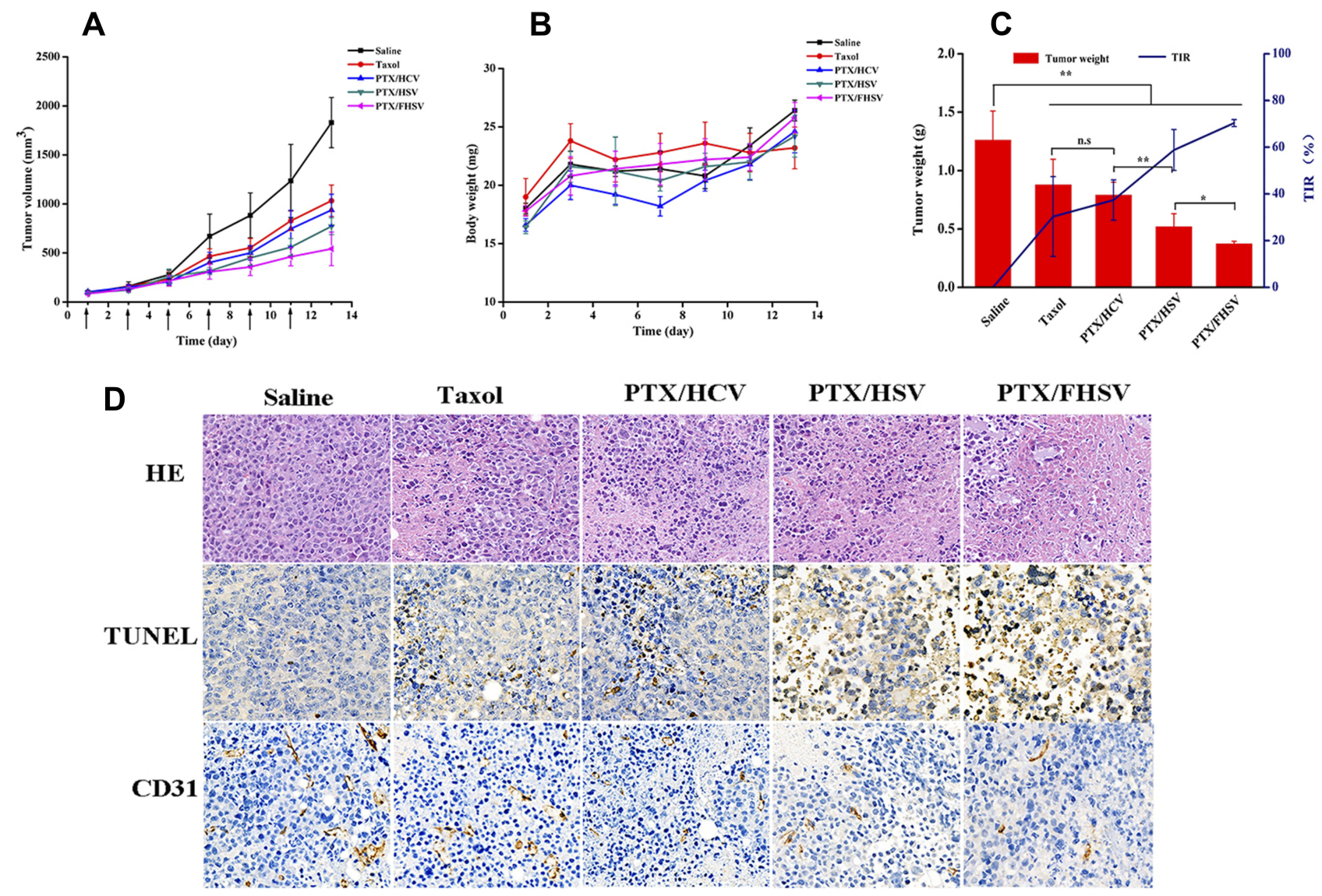

Figure 8 In vivo antitumor efficacy against SI80 tumor xenograft model. (A) Tumor growth curves of mice treated with saline, Taxol and PTX-loaded micelles. (B) Body weight changes of mice. (C) Tumor weight and TIR of different groups after the last treatments $(n=5) . * p<0.05, * * p<0.0$ I, ns, $p>0.05$. (D) H\&E, TUNEL and CD3I analyses of excised tumors after the last treatments.

growth inhibition in comparison to the saline group. For tumor suppression ability, Taxol and PTX/HCV only presented moderate antitumor activity, leading to tumor volumes of $1032.47 \pm 160.42 \mathrm{~mm}^{3}$ and $937.29 \pm 162.36 \mathrm{~mm}^{3}$ on day 13 , respectively. Notably, although the surface properties and particle size of redox-sensitive PTX/HSV micelles and redox-insensitive PTX/HCV micelles, PTX/HSV micelles exhibited more promising antitumor ability than PTX/HCV micelles $(p<0.01)$, suggesting the advantage of reductiontriggered intracellular drug release strategy. Furthermore, PTX/FHSV micelles exhibited the most outstanding reduction in tumor size compared to other groups, which was in line with the results from MTT and apoptosis assays. The tumor inhibition rates (TIR) were also calculated (Figure $8 \mathrm{C})$. It demonstrated that the highest TIR was observed in the PTX/FHSV group, with a value of $70.33 \% \pm 1.52 \%$, which was remarkably higher than that of PTX/HSV group $(58.78 \% \pm 8.73 \%, p<0.05), \mathrm{PTX} / \mathrm{HCV}$ group $(36.36 \pm$ $8.66 \%, p<0.001)$ and Taxol group $(30.32 \% \pm 17.12 \%$, $p<0.001)$. Additionally, the body weight curve of mice during the administration course is presented in Figure 8B. No significant differences in body weight suggested the safety and negligible systemic toxicity of polymeric micelles.

For the purpose of further evaluating the tumor suppression mechanisms of PTX-loaded micelles, necrosis, apoptosis and angiogenesis in the tumor specimens of different treated groups were analyzed by histology and immunohistochemical studies (Figure 8D). H\&E staining revealed that different degrees of cell necrosis were observed on day 13 after administration with different PTX-loaded formulations; in particular, almost completely necrotic tumor cells were found in the PTX/FHSV group. In TUNEL staining, the results were in coincidence with those of $\mathrm{H} \& \mathrm{E}$ staining, and the tumor slide of PTX/FHSV group yielded more dark brown apoptotic areas than the other treated groups, which further confirmed the superior antitumor potency of PTX/FHSV micelles. Rapid tumor proliferation is always accompanied by angiogenesis to meet the needs of tumor cells for oxygen and nutrition. ${ }^{47}$ Therefore, CD31 staining of tumor tissues was executed to evaluate the anti-angiogenic 


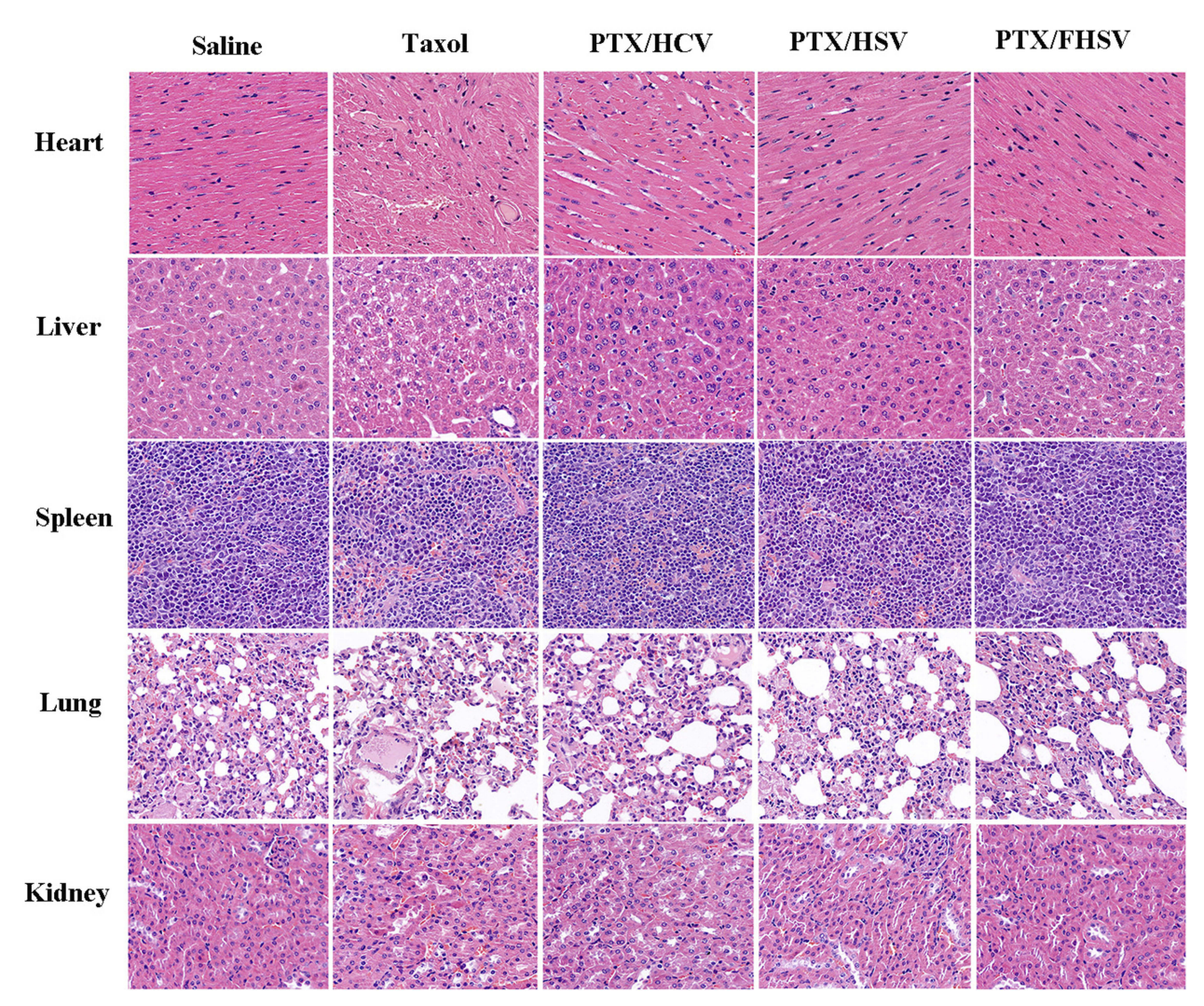

Figure 9 H\&E staining of major organs at the end of treatments.

capacity of different PTX-loaded formulations. According to Figure 8D, the tumor microvessel density of the PTX/FHSV group was less than that of the other treated groups, suggesting the strongest anti-angiogenic ability of PTX/FHSV micelles at the tumor sites. These results showed that PTX/ FHSV micelles could effectively prevent angiogenesis and promote the apoptosis and necrosis of tumor cells, followed by the growth inhibition of tumors.

Minimal damage of normal organs was essential during the chemotherapy period. It was obvious that pathological changes were not significant in these major tissues of mice administered with PTX-loaded micelles (Figure 9). In contrast, the cardiomyocytes of the mice treated with Taxol exhibited myocardial fiber breakage and vacuolization. Taken together, the well-designed micelles were endowed with superior security owing to their excellent selectivity between tumors and normal organs.

\section{Conclusions}

In summary, we successfully designed an innovative amphiphilic block polymer-FHSV polymer with dual receptor-targeted ability and reduction sensitivity to selectively deliver anticancer drugs for tumor therapy.
The first-line chemotherapeutic drug PTX was successfully encapsulated into the hydrophobic cores of FHSV to self-assemble into uniformly near-spherical micelles. As expected, the loaded PTX could be released completely from PTX/FHSV micelles under stimulation with 10 mM GSH. In in vitro cytological studies, the PTX/FHSV micelles revealed the most superior cytotoxicity to MCF7 cells by means of dual receptor-mediated cellular uptake and precise release in the cytoplasm. More importantly, the in vivo study results demonstrated that FHSV micelles exhibited enhanced active targeting ability to promote drug accumulation in tumor regions, which resulted in the best therapeutic effect on solid tumors and reduced toxicity to normal organs. Thus, selective redox-sensitive FHSV micelles have greatly potential applications for tumor therapy.

\section{Acknowledgments}

This work was supported by the National Natural Science Foundation of China (No. 81703709, 81703425), China Postdoctoral Science Foundation (No. 2018M641716) and Natural Science Foundation of Liaoning Province (NO. 2019ZD-0433). 


\section{Disclosure}

Fen Chen is employed by Zhejiang Jingxin Pharmaceutical Co., Ltd. The authors report no other conflicts of interest in this work.

\section{References}

1. Zhang Y, Zhang C, Chen J, et al. Trackable mitochondria-targeting nanomicellar loaded with doxorubicin for overcoming drug resistance. ACS Appl Mater Interfaces. 2017;9(30):25152-25163. doi:10.1021/acsami.7b07219

2. Wang $\mathrm{K}$, Yang B, Ye $\mathrm{H}$, et al. Self-strengthened oxidation-responsive bioactivating prodrug-nanosystem with sequential and synergistically facilitated drug release for treatment of breast cancer. ACS Appl Mater Interfaces. 2019;11:18914-18922. doi:10.1021/acsami.9b03056

3. Herrera DA, Ashai N, Perez-Soler R, Cheng H. Nanoparticle albumin bound-paclitaxel for treatment of advanced non-small cell lung cancer: an evaluation of the clinical evidence. Expert Opin Pharmacother. 2018;20(1):95-102. doi:10.1080/ 14656566.2018.1546290

4. Mekhail TM, Markman M. Paclitaxel in cancer therapy. Expert Opin Pharmacother. 2002;3(6):755-766. doi:10.1517/14656566.3.6.755

5. Rezazadeh M, Emami J, Hassanzadeh F, et al. Targeted nanostructured lipid carriers for delivery of paclitaxel to cancer cells: preparation, characterization, and cell toxicity. Curr Drug Deliv. 2017;14 (8):1189-1200. doi:10.2174/1567201814666170503143646

6. Gorain B, Choudhury H, Pandey M, Kesharwani P. Paclitaxel loaded vitamin E-TPGS nanoparticles for cancer therapy. Mater Sci Eng C. 2018;91:868-880. doi:10.1016/j.msec.2018.05.054

7. Sun B, Luo C, Yu H, et al. Disulfide bond-driven oxidation- and reduction-responsive prodrug nanoassemblies for cancer therapy. Nano Lett. 2018;18:3643-3650. doi:10.1021/acs.nanolett.8b00737

8. Luo C, Wang Y, Chen Q, et al. Advances of paclitaxel formulations based on nanosystem delivery technology. Mini-Rev Med Chem. 2012;12(5):434-444. doi:10.2174/138955712800493924

9. Chakravarthi SS, De S, Miller DW, Robinson DH. Comparison of anti-tumor efficacy of paclitaxel delivered in nano- and microparticles. Int J Pharm. 2010;38(1-2):37-44. doi:10.1016/j. ijpharm.2009.09.004

10. Ravar F, Saadat E, Gholami M, et al. Hyaluronic acid-coated liposomes for targeted delivery of paclitaxel, in-vitro characterization and in-vivo evaluation. J Control Release. 2016;229:10-22. doi:10.1016/ j.jconrel.2016.03.012

11. Meng Z, Lv Q, Lu J, et al. Prodrug strategies for paclitaxel. Int J Mol Sci. 2016;17(5):796-818. doi:10.3390/ijms 17050796

12. Monteiro LOF, Malachias Â, Pound-Lana G, et al. paclitaxel-loaded ph-sensitive liposome: new insights on structural and physicochemical characterization. Langmuir. 2018;34(20):5728-5737. doi:10.1021/acs.langmuir.8b00411

13. Banerjee I, De K, Mukherjee D, et al. Paclitaxel-loaded solid lipid nanoparticles modified with Tyr-3-octreotide for enhanced anti-angiogenic and anti-glioma therapy. Acta Biomater. 2016;38:69-81. doi:10.1016/j.actbio.2016.04.026

14. Emami J, Rezazadeh M, Hasanzadeh F, et al. Development and in vitro/in vivo evaluation of a novel targeted polymeric micelle for delivery of paclitaxel. Int $J$ Biol Macromol. 2015;80:29-40. doi:10.1016/j.ijbiomac.2015.05.062

15. Fang J, Nakamura H, Maeda $H$. The EPR effect: unique features of tumor blood vessels for drug delivery, factors involved, and limitations and augmentation of the effect. Adv Drug Deliv Rev. 2010;63:136-151. doi:10.1016/j.addr.2010.04.009

16. Bertrand N, Wu J, Xu X, Kamaly N, Farokhzad OC. Cancer nanotechnology: the impact of passive and active targeting in the era of modern cancer biology. Adv Drug Deliv Rev. 2014;66:2-25. doi:10.1016/j.addr.2013.11.009
17. Mao J, Ran D, Xie C, Shen Q, Wang S, Lu W. EGFR/EGFRvIII dual-targeting peptide-mediated drug delivery for enhanced glioma therapy. ACS Appl Mater Interfaces. 2017;9(29):24462-24475. doi:10.1021/acsami.7b05617

18. Yue J, Liu S, Wang R, et al. Transferrin-conjugated micelles: enhanced accumulation and antitumor effect for transferrin-receptoroverexpressing cancer models. Mol Pharm. 2012;9(7):1919-1931. doi:10.1021/mp300213g

19. Cheng L, Jiang Y, Xie Y, Qiu L, Yang Q, Lu H. Novel amphiphilic folic acid-cholesterol-chitosan micelles for paclitaxel delivery. Oncotarget. 2017;8(2):3315-3326. doi:10.18632/oncotarget.13757

20. Yin T, Wang J, Yin L, et al. Redox-sensitive hyaluronic acid-paclitaxel conjugate micelles with high physical drug loading for efficient tumor therapy. Polym Chem. 2015;6:8047-8059. doi:10.1039/ C5PY01355K

21. Huang G, Huang H. Application of hyaluronic acid as carriers in drug delivery. Drug Deliv. 2018;25(1):766-772. doi:10.1080/ 10717544.2018.1450910

22. Arpicco S, Milla P, Stella B, Dosio F. Hyaluronic acid conjugates as vectors for the active targeting of drugs, genes and nanocomposites in cancer treatment. Molecules. 2014;19(3):3193-3230. doi:10.3390/ molecules 19033193

23. Dosio F, Arpicco S, Stella B, Fattal E. Hyaluronic acid for anticancer drug and nucleic acid delivery. Adv Drug Deliv Rev. 2016;97:204-236. doi:10.1016/j.addr.2015.11.011

24. Li J, Huo M, Wang J, et al. Redox-sensitive micelles self-assembled from amphiphilic hyaluronic acid-deoxycholic acid conjugates for targeted intracellular delivery of paclitaxel. Biomaterials. 2012;33 (7):2310-2320. doi:10.1016/j.biomaterials.2011.11.022

25. Lee SJ, Jeong YI. Hybrid nanoparticles based on chlorin e6-conjugated hyaluronic acid-poly(L-histidine) copolymer for theranostic application to tumors. J Mater Chem B. 2018;6 (18):2851-2859. doi:10.1039/C7TB03068A

26. Jeong GW, Jeong YI, Nah JW. Triggered doxorubicin release using redox-sensitive hyaluronic acid-g-stearic acid micelles for targeted cancer therapy. Carbohydr Polym. 2019;209:161-171. doi:10.1016/j. carbpol.2019.01.018

27. Hu D, Mezghrani O, Zhang L, Chen Y, Ke X, Ci T. GE11 peptide modified and reduction-responsive hyaluronic acid-based nanoparticles induced higher efficacy of doxorubicin for breast carcinoma therapy. Int J Nanomed. 2016;11:5125-5147. doi:10.2147/IJN. S113469

28. Chen J, Ouyang J, Chen Q, et al. EGFR and CD44 dual-targeted multifunctional hyaluronic acid nanogels boost protein delivery to ovarian and breast cancers in vitro and in vivo. ACS Appl Mater Interfaces. 2017;9(28):24140-24147. doi:10.1021/acsami.7b06879

29. Sawant RR, Jhaveri AM, Koshkaryev A, Qureshi F, Torchilin VP. The effect of dual ligand-targeted micelles on the delivery and efficacy of poorly soluble drug for cancer therapy. J Drug Target. 2013;21(7):630-638. doi:10.3109/1061186X.2013.789032

30. Xu L, Bai Q, Zhang X, Yang H. Folate-mediated chemotherapy and diagnostics: an updated review and outlook. J Control Release. 2017;252:73-82. doi:10.1016/j.jconrel.2017.02.023

31. Cheung A, Bax HJ, Josephs DH, et al. Targeting folate receptor alpha for cancer treatment. Oncotarget. 2016;7(32):52553-52574. doi:10.18632/oncotarget.9651

32. Yan Y, Dong Y, Yue S, Qiu X, Sun H, Zhong Z. Dually active targeting nanomedicines based on a direct conjugate of two purely natural ligands for potent chemotherapy of ovarian tumors. ACS Appl Mater Interfaces. 2019;11(50):46548-46557. doi:10.1021/ acsami.9b17223

33. Elamin KM, Motoyama K, Higashi T, Yamashita Y, Tokuda A, Arima H. Dual targeting system by supramolecular complex of folate-conjugated methyl- $\beta$-cyclodextrin with adamantane-grafted hyaluronic acid for the treatment of colorectal cancer. Int $\mathrm{J} \mathrm{Biol}$ Macromol. 2018;113:386-394. doi:10.1016/j.ijbiomac.2018.02.149 
34. Liu Y, Sun J, Cao W, et al. Dual targeting folate-conjugated hyaluronic acid polymeric micelles for paclitaxel delivery. Int $J$ Pharm. 2011;421(1):160-169. doi:10.1016/j.ijpharm.2011.09.006

35. Lee JY, Termsarasab U, Park JH, et al. Dual CD44 and folate receptor-targeted nanoparticles for cancer diagnosis and anticancer drug delivery. J Control Release. 2016;236:38-46. doi:10.1016/j. jconrel.2016.06.021

36. Li F, Chen W, You B, et al. Enhanced cellular internalization and on-demand intracellular release of doxorubicin by stepwise $\mathrm{pH}-/$ reduction-responsive nanoparticles. ACS Appl Mater Interfaces. 2016;8(47):32146-32158. doi:10.1021/acsami.6b09604

37. Hong SH, Larocque K, Jaunky DB, Piekny A, Oh JK. Dual disassembly and biological evaluation of enzyme/oxidation-responsive polyester-based nanoparticulates for tumor-targeting delivery. Colloids Surf B Biointerfaces. 2018;172:608-617. doi:10.1016/j. colsurfb.2018.09.013

38. Yu C, Gao C, Lü S, Chen C, Huang Y, Liu M. Redox-responsive shell-sheddable micelles self-assembled from amphiphilic chondroitin sulfate-cholesterol conjugates for triggered intracellular drug release. Chem Eng J. 2013;228:290-299. doi:10.1016/j. cej.2013.04.083

39. Raza A, Hayat U, Rasheed T, Bilal M, Iqbal HMN. Redox-responsive nano-carriers as tumor-targeted drug delivery systems. Eur J Med Chem. 2018;157:705-715. doi:10.1016/j.ejmech.2018.08.034

40. Duhem N, Danhier F, Preat V. Vitamin E-based nanomedicines for anti-cancer drug delivery. J Control Release. 2014;182:33-44. doi:10.1016/j.jconrel.2014.03.009

41. Liang D, Wang A, Yang Z, Liu Y, Qi X. Enhance Cancer Cell Recognition and Overcome Drug Resistance Using Hyaluronic Acid and alpha-Tocopheryl Succinate Based Multifunctional Nanoparticles. Mol Pharm. 2015;12(6):2189-2202. doi:10.1021/acs. molpharmaceut.5b00129

42. Liu Y, Zong Y, Yang Z, et al. dual-targeted controlled delivery based on folic acid modified pectin-based nanoparticles for combination therapy of liver cancer. ACS Sustain Chem Eng. 2019;7 (3):3614-3623. doi:10.1021/acssuschemeng.8b06586

43. Gao Y, Sarfraz MK, Clas SD, Roa W, Löbenberg R. Hyaluronic acid-tocopherol succinate-based self-assembling micelles for targeted delivery of rifampicin to alveolar macrophages. $J$ Biomed Nanotechnol. 2015;11(8):1312-1329. doi:10.1166/jbn.2015.2091

44. Xu J, Han Y, Pei M, et al. Multi-functionalized hyaluronic acid nanogels crosslinked with carbon dots as dual receptor-mediated targeting tumor theranostics. Carbohydr Polym. 2016;152:391-397. doi:10.1016/j.carbpol.2016.06.109

45. Ganesh S, Iyer AK, Morrissey DV, et al. Hyaluronic acid based self-assembling nanosystems for CD44 target mediated siRNA delivery to solid tumors. Biomaterials. 2013;34(13):3489-3502. doi:10.1016/j.biomaterials.2013.01.077
46. Zhong Y, Zhang J, Cheng R, et al. Reversibly crosslinked hyaluronic acid nanoparticles for active targeting and intelligent delivery of doxorubicin to drug resistant $\mathrm{CD} 44+$ human breast tumor xenografts. J Control Release. 2015;205:144-154. doi:10.1016/j. jconrel.2015.01.012

47. Zhang J, Zhao X, Chen Q, et al. Systematic evaluation of multifunctional paclitaxel-loaded polymeric mixed micelles as a potential anticancer remedy to overcome multidrug resistance. Acta Biomater. 2017;50:381-395. doi:10.1016/j.actbio.2016.12.021

48. Song S, Qi H, Xu J, et al. Hyaluronan-based nanocarriers with CD44-overexpressed cancer cell targeting. Pharm Res. 2014;31 (11):2988-3005. doi:10.1007/s11095-014-1393-4

49. Lin J, Zhao C, Liu C, et al. Redox-responsive F127-folate/F127disulfide bond-d- $\alpha$-tocopheryl polyethylene glycol 1000 succinate/ P123 mixed micelles loaded with paclitaxel for the reversal of multidrug resistance in tumors. Int J Nanomed. 2018;13:805-830. doi:10.2147/IJN.S152395

50. Choi KY, Jeon EJ, Yoon HY, et al. Theranostic nanoparticles based on PEGylated hyaluronic acid for the diagnosis, therapy and monitoring of colon cancer. Biomaterials. 2012;33(26):6186-6193. doi:10.1016/j.biomaterials.2012.05.029

51. Mezghrani O, Tang Y, Ke X, et al. Hepatocellular carcinoma dually-targeted nanoparticles for reduction triggered intracellular delivery of doxorubicin. Int $J$ Pharm. 2015;478(2):553-568. doi:10.1016/j.ijpharm.2014.10.041

52. Li J, Yin T, Wang L, Yin L, Zhou J, Huo M. Biological evaluation of redox-sensitive micelles based on hyaluronic acid-deoxycholic acid conjugates for tumor-specific delivery of paclitaxel. Int $J$ Pharm. 2015;483(1-2):38-48. doi:10.1016/j.ijpharm.2015.02.002

53. Zhao H, Yang C, Yan X. Fabrication and bioconjugation of $\mathrm{B}^{\mathrm{III}}$ and $\mathrm{Cr}^{\mathrm{III}}$ co-doped $\mathrm{ZnGa} 2 \mathrm{O} 4$ persistent luminescent nanoparticles for dual-targeted cancer bioimaging. Nanoscale. 2016;8 (45):18987-18994. doi:10.1039/C6NR06259H

54. Park HK, Lee SJ, Oh JS, Lee SG, Jeong YI, Lee HC. Smart nanoparticles based on hyaluronic acid for redox-responsive and CD44 receptor-mediated targeting of tumor. Nanoscale Res Lett. 2015;10 (1):288. doi:10.1186/s11671-015-0981-5

55. Galbiati A, Tabolacci C, Blasco MDR, et al. Targeting tumor cells through chitosan-folate modified microcapsules loaded with camptothecin. Bioconjug Chem. 2011;22(6):1066-1072. doi:10.1021/bc100546s

56. Liang D, Su H, Liu Y, Wang A, Qi X. Tumor-specific penetrating peptides-functionalized hyaluronic acid-D- $\alpha$-tocopheryl succinate based nanoparticles for multi-task delivery to invasive cancers. Biomaterials. 2015;71:11-23. doi:10.1016/j.biomaterials.2015.08.035

57. Parker N, Turk MJ, Westrick E, et al. Folate receptor expression in carcinomas and normal tissues determined by a quantitative radioligand binding assay. Anal Biochem. 2005;338(2):284-293. doi:10.1016/j.ab.2004.12.026
International Journal of Nanomedicine

\section{Publish your work in this journal}

The International Journal of Nanomedicine is an international, peerreviewed journal focusing on the application of nanotechnology in diagnostics, therapeutics, and drug delivery systems throughout the biomedical field. This journal is indexed on PubMed Central, MedLine, CAS, SciSearch ${ }^{\circledR}$, Current Contents ${ }^{\circledR} /$ Clinical Medicine,
Journal Citation Reports/Science Edition, EMBase, Scopus and the Elsevier Bibliographic databases. The manuscript management system is completely online and includes a very quick and fair peer-review system, which is all easy to use. Visit http://www.dovepress.com/ testimonials.php to read real quotes from published authors. 